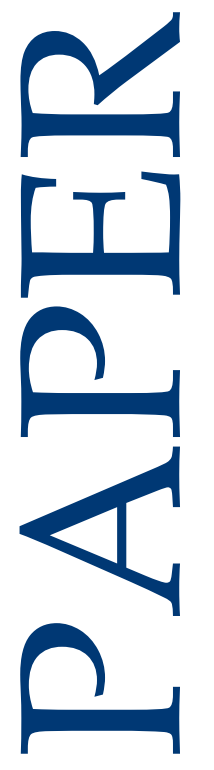

April $2016 \square$ RFF DP 16-12

\title{
Strategic Subsidies for Green Goods
}

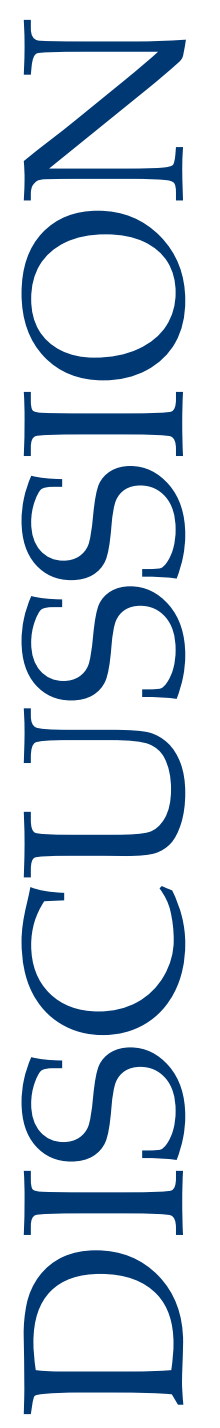

Carolyn Fischer

1616 P St. NW

Washington, DC 20036

202-328-5000 www.rff.org

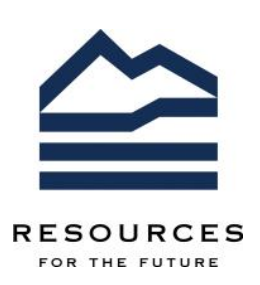




\title{
Strategic Subsidies for Green Goods
}

\author{
Carolyn Fischer
}

\begin{abstract}
Globally and locally, government support policies for green goods (like renewable energy) are much more popular internationally than raising the cost of bads (as through carbon taxes). These support policies may encourage downstream consumption (renewable energy deployment) or upstream development and manufacturing of those technologies. The use of subsidies - particularly upstream ones - is disciplined by World Trade Organization agreements, and its subsidies code lacks exceptions for transboundary externalities such as human health or resource conservation, including those related to combating global climate change. The strategic trade literature has devoted little attention to the range of market failures related to green goods. This paper considers the market for a new environmental good that when consumed downstream may provide external benefits such as reduced emissions. The technology is traded internationally but provided by a limited set of upstream suppliers that may operate in imperfect markets, such as with market power or external scale economies. We examine the national incentives and global rationales for offering production and consumption subsidies in producer countries, allowing that some of the downstream market may lie in nonregulating third-party countries. Although technology producer countries can benefit from restraints on upstream subsidies, global welfare is higher without them, and market failures imply that optimal subsidies are even higher. We supplement the analysis with numerical simulations of the case of renewable energy, exploring optimal subsidies for the major renewable energy producing and consuming regions and the cost of restrictions on upstream subsidies.
\end{abstract}

Key Words: international trade, subsidies, imperfect competition, externalities, emissions leakage

JEL Classification Numbers: F13, F18, H21, Q5

(C) 2016 Resources for the Future. All rights reserved. No portion of this paper may be reproduced without permission of the author.

Discussion papers are research materials circulated by their authors for purposes of information and discussion. They have not necessarily undergone formal peer review. 


\section{Contents}

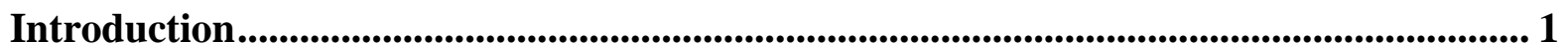

Model Framework .............................................................................................................................. 5

Market Failures.............................................................................................................................................. 8

Imperfect Competition …………………......................................................... 8

Downstream Externalities ..................................................................................... 12

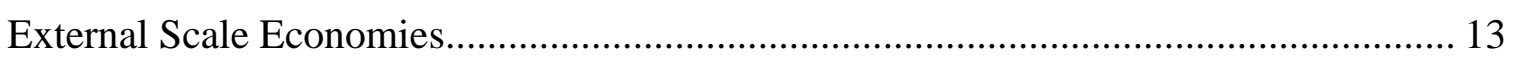

Combining Market Failures: An Application to Renewable Energy................................... 16

Numerical Model .............................................................................................. 16

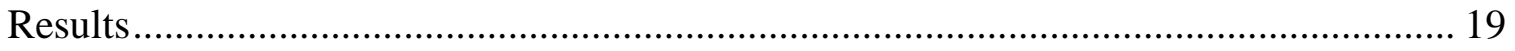

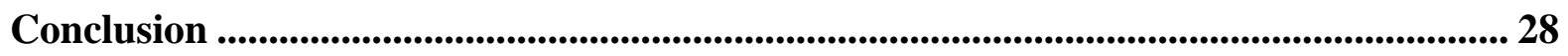

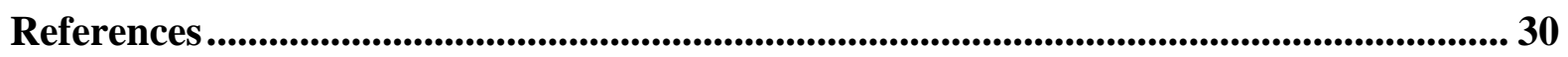

Appendix ............................................................................................................................................................ 34 


\title{
Strategic Subsidies for Green Goods
}

\author{
Carolyn Fischer ${ }^{1}$
}

\section{Introduction}

World Trade Organization (WTO) rules create restrictions on industrial policies that distort trade, particularly subsidies. In contrast to the General Agreement on Tariffs and Trade, the Agreement on Subsidies and Countervailing Measures (the subsidies code) lacks exceptions for transboundary externalities like human health or resource conservation, including those related to combating global climate change. Yet policies that support green goods (like renewable energy) are much more popular internationally than policies that impose a cost on bads (like carbon taxes). As the global community moves toward addressing important crossborder environmental and health challenges, does the multilateral trade regime need to reconsider its approach to subsidies for green goods?

Climate policies offer a striking example of these tensions over subsidies. Economists have reached a consensus that the best way to reduce greenhouse gas (GHG) emissions is to put a global price on those emissions (much as scientists have reached a broad consensus over the existence and potential perils of global climate change). However, whereas only about 40 countries and 20 subnational jurisdictions are using or planning to implement carbon pricing (World Bank 2014), nearly 100 countries and countless subnational jurisdictions offer financial incentives for renewable energy (IEA/IRENA 2015). Indeed, all the jurisdictions with carbon pricing also rely on renewable energy support. The measures range from downstream measures that support deployment to upstream incentives for R\&D and manufacturing. In 2012, the value

\footnotetext{
${ }^{1}$ Resources for the Future, Gothenburg University, FEEM, and CESifo Research Network. Mailing address: RFF, 1616 P Street NW, Washington, DC 20036. Email: fischer@ rff.org.

This work was conducted under the European Community's Marie Skłodowska-Curie International Incoming Fellowship, "STRATECHPOL - Strategic Clean Technology Policies for Climate Change," financed under the EC Grant Agreement PIIF-GA-2013-623783, and with the hospitality of the Fondazione Eni Enrico Mattei (FEEM). The numerical simulations are made possible by prior work funded by US Environmental Protection Agency Grant 83413401 and the Swedish Foundation for Strategic Environmental Research (MISTRA) INDIGO program. Special thanks to conference and seminar participants from the Toulouse School of Economics, the Grantham Research Institute, Hamburg University, FEEM, European University Institute, École Polytechnique, ETH Zurich, University of Bern, and Politecnico Milano.
} 
of European Union (EU) interventions for renewable energy exceeded the value of all the emissions trading allowances allocated for the year. ${ }^{2}$

In some cases, the subsidies are becoming substantial and distorting enough to raise trade concerns. When Ontario instituted a feed-in-tariff with domestic content requirements (in essence, leveraging the downstream deployment subsidy to support upstream local manufacturing), the European Union, Japan, and others complained, and the WTO panel and appellate body struck down the policy (Charnovitz and Fischer 2014). In another set of cases, the European Union and United States have brought antidumping and antisubsidy complaints against China, charging that large Chinese subsidies in the form of cheap loans, land, and capital to photovoltaic producers constitute illegal aid. WTO (2011) has stated that its rules do not hinder supporting the deployment and diffusion of green technologies. Downstream subsidies can indeed be designed in a nondiscriminatory fashion, but upstream policies almost necessarily offer preferential treatment to domestic producers. Thus, it is important to understand whether an economic rationale exists to carve out exceptions in the WTO subsidies code to make room for certain kinds of green industrial policy (Rubini 2012).

Export and production subsidies have been studied in the strategic trade literature. An influential early example was the pair of studies by Spencer and Brander (1983) and Brander and Spencer (1985), who study a Cournot duopoly of producer countries exporting to a third market. Dixit (1984) extends their analysis to multiple firms, Krugman (1984) to the case of increasing returns to scale, and Leahy and Neary (1999) to R\&D spillovers. Eaton and Grossman (1986) compare Cournot with Bertrand competition. These studies tend to focus on the strategic interest of the producer countries, typically exporting to third countries, and whether their joint interests are better served by restricting trade interventions. However, questions of global welfare or correcting market failures - important aspects of international environmental policy — are deemphasized or ignored. Indeed, we will show that changing this emphasis can change the policy implications for subsidies.

\footnotetext{
2 Alberici et al. (2014) find that "in 2012, the total value of public interventions in energy (excluding transport) in the EU-28 is €2012 122 billion," with €2012 41 billion for renewable energy (p. i-ii). Meanwhile, in 2012, the annual allocation of allowances was 2170 million; at an average annual price of roughly $€ 7$, the value of the annual cap was just over $€ 201215$ billion. Sources: http://www.eex.com/en/market-data/emission-allowances/auctionmarket/european-emission-allowances-auction/european-emission-allowances-auction-download and http://www.eea.europa.eu/data-and-maps/data/data-viewers/emissions-trading-viewer.
} 
Market failures have been an important focus of studies of overlapping climate policies, their interactions, and costs (see, e.g., Fischer and Preonas 2010, Fischer et al. 2013, and Fischer and Newell 2008 for the electricity sector; and De Gorter and Just 2010 and Anderson et al. 2016 for biofuels; and a broad review in OECD 2011). Indeed, in the absence of other market failures, renewable energy subsidies increase the costs of meeting an emissions target (Böhringer and Rosendahl 2010). Fischer et al. (2013) explore the extent to which knowledge market failures or spillovers justify subsidies to correct the underprovision of R\&D and learning by doing by private markets. In an application to the US electricity sector, they find optimal learning (i.e., deployment) subsidies are plausibly in the range of 1 cent/kWh or less for conventional renewable energy technologies like wind, and a higher but still modest range of 4-6 cents/kWh for solar. Hübler et al. (2015) look at second-best renewable energy policies for Europe and find that policy constraints can justify additional deployment support, but the optimal levels are again quite modest, since learning in renewables is still less cost-effective than other mitigation options in the electricity sector. Importantly, all of these studies focus on a single region and ignore the possibility of international linkages through trade in renewable energy technologies.

Carbon leakage - when reduction efforts taken in one region may, through global trade, be undone to some extent by changes in emissions abroad — may be another reason why national policymakers like to supplement or even substitute carbon pricing with low-carbon technology policies. Keeping carbon prices low for industry can avoid damaging the competitiveness of energy-intensive, trade-exposed sectors. Furthermore, spillovers from the development of green technologies can lower mitigation costs for other countries (Gerlagh and Kuik 2014; Barker et al. 2007; Golombek and Hoel 2004), though there can be strategic reasons to avoid transferring clean technologies, even if it would reduce global emissions, when the polluting goods are traded (Glachant et al. 2016).

The characteristics of upstream markets for the provision of clean technologies may offer additional rationales for support. Low-carbon energy technologies are newer, the number of suppliers is relatively small, and patent restrictions still play an important role, as do the emergence of scale economies. As such, the typical upstream market can hardly be considered perfectly competitive (Requate 2005), and interventions may be justified to address market failures in the provision of renewable energy technologies.

Few papers in the environmental economics literature have distinguished between upstream technology suppliers and downstream adopters in a model of international trade. This distinction is important, since upstream interventions that lower supplier costs then lower the global price of a green good, increasing consumption abroad, whereas downstream subsidies 
drive up global prices, reducing foreign consumption. Thus, when consumption of the green good is associated with avoided emissions, the two policies have different implications for foreign emissions. Greaker and Rosendahl (2008) consider strategic emissions regulation when upstream markets are imperfect, finding that an individual country may want to impose an excessively stringent environmental policy in order to reduce the markup of technology suppliers, and hence increase the diffusion of these technologies. Fischer et al. (2014) consider subsidies for end-of-pipe abatement technology in a two-country model with Cournot competitors upstream and competitive trade-exposed industries downstream, identifying a global and strategic advantage to upstream subsidies. ${ }^{3}$

This paper generalizes the problem of upstream and downstream market failures and trade. It takes a far more comprehensive approach than previous theoretical studies in the environmental or trade literatures, allowing for multiple regions and firms, multiple upstream market failures (imperfect competition and scale effects with spillovers), and different downstream externalities. Using linear forms for supply and demand curves, closed-form unique solutions for optimal and strategic Nash subsidies are derived as a function of the market failures and parameters of interest. A calibrated numerical exercise then estimates the levels and welfare effects of optimal and strategic equilibrium subsidies for the case of renewable energy and explores their sensitivity to different market failure assumptions.

Renewable energy is an interesting application because the technologies are traded internationally and arguably are characterized by multiple market failures. For example, the top four producers of wind turbines (firms located in the United States and Europe) supply roughly half the global market; 70 percent of global production occurs in the United States, Europe, and China. Production of solar modules distributed across more manufacturers, but more than 30 percent occurs in China; scale economies and learning are important factors in that sector (Nemet 2006, 2009; Swanson 2006; Schaeffer 2004; Bruton 2002). The external benefits of renewable energy deployment are also highly sensitive to where and how they are applied. The extent to which they reduce emissions depends both on a country's supply mix of polluting energy sources

\footnotetext{
3 Also for the duopoly case, Fischer et al. (2016) note the importance of the regulatory setting downstream. They consider the setting of renewable energy technology when downstream markets are regulated with renewable portfolio standards (market share mandates). In this case, the global emissions effects are opposite: a decrease in the global price allows dirty generation to expand when the portfolio standard becomes less binding.
} 
and on the downstream policy environment: whether the country values the social costs of carbon and to what extent it prices its emissions.

We find several potential rationales for subsidies, particularly for upstream production, not only for individual countries but also from a global perspective. In particular, we find that strategically determined subsidies may actually undercorrect market failures, rather than be overly generous to domestic producers.

In the next section we describe our general model framework. Next we derive results isolating the different market failures. Then we use a numerical model to explore optimal subsidies for renewable energy technologies used in the electricity sector. The final section concludes.

\section{Model Framework}

We present a partial equilibrium model of a single sector in which production and consumption of an identical environmental good (e.g., a wind turbine or solar panel) occurs across multiple countries with trade. Because we have in mind a relatively small sector in the economy, we forego modeling general equilibrium effects, noting that under standard assumptions the results carry through in a general equilibrium model with terms of trade. ${ }^{4}$

Consider a world divided into three regions: a domestic producing and consuming region (1), a foreign producing and consuming region (2), and a third-party consuming region (3). Markets are decentralized, and the products are assumed to be identical; this assumption allows for consistency of representation across the different market failures, as well as for the parameterization of downstream demand for renewable energy technology in our numerical application.

Each producing region $i=\{1,2\}$ may offer to subsidize downstream deployment by $\eta_{i}$ and/or to lower the unit delivery costs of the upstream technology firms by $\gamma_{i}$. We assume the third country has no subsidy policies (e.g., a developing country without climate policy obligations); thus, $\eta_{3}=0$.

\footnotetext{
${ }^{4}$ Brander and Spencer (1985) show this with an additive utility function including a perfectly competitive numeraire good.
} 
Although certain results could be derived with general functional forms, we choose to use common functional forms to derive closed-form solutions for all our equilibria of interest. ${ }^{5}$ These simplifications allow us to evaluate equilibria with multiple policies and to compare optimal and constrained strategies across heterogeneous regions and with a social planner. We subsequently use the same forms in a parameterized numerical model.

Let us assume the following linear demand functions for the technology in each country, where $m_{i}$ is a measure of downstream market share of region $i$ (and $\sum_{i} m_{i}=1$ ). ${ }^{6}$

$$
x_{i}=m_{i}\left(\frac{a-\left(P-\eta_{i}\right)}{b}\right)
$$

Total demand is $X=x_{1}+x_{2}+x_{3}$. This gives us an inverse demand function facing the upstream producers of $P=A-B X$, where the slope equals the identical individual slopes $B=b$, and the intercept equals the weighted average intercept $A=a+\bar{\eta}$, where $\bar{\eta}=\sum_{i} m_{i} \eta_{i}$.

Consumer surplus is the area under each linear demand curve above the consumer price:

$$
C S_{i}=\frac{m_{i}\left(a-\left(P-\eta_{i}\right)\right)^{2}}{2 b}
$$

Governments place a value on domestic profits, $\Pi_{i}$, domestic consumer surplus, $C S_{i}$, net revenues $T R_{i}$, and global downstream externalities, $E_{G}$. They ignore effects on foreign producer profits and consumer welfare, and possibly undervalue external benefits $\left(v_{i}<v_{G}\right)$. (Since the environmental spillover case is the most interesting, let us assume that the external benefits are reductions in a global pollutant like greenhouse gases, as opposed to a local pollutant). ${ }^{7}$

Welfare for each of the three regions is

\footnotetext{
${ }^{5}$ Linear demand and constant marginal costs are explored in Dixit (1984), and Spencer and Brander(1983); Eaton and Grossman (1986), while using general functional forms, note that linear demand implies "normal" slopes of the reaction curves, which ensures existence, uniqueness, and stability of equilibria.

${ }^{6}$ One could vary other demand parameters by country, as we do in the numerical simulations, but the strategic issues related to heterogeneous downstream demand are captured sufficiently by the parameter $m$.

${ }^{7}$ For example, EPA calculates that the marginal benefits of emissions reductions in the United States domestically are between $\$ 1$ and $\$ 4$, but global marginal benefits are in the range of $\$ 40$ per ton CO2 (Metcalf and Stock 2015). EPA guidelines are to use the global social cost of carbon.
} 


$$
\begin{aligned}
W_{1} & =\Pi_{1}+C S_{1}+T R_{1}+v_{1} E_{G} \\
W_{2} & =\Pi_{2}+C S_{2}+T R_{2}+v_{2} E_{G} \\
W_{3} & =C S_{3}+v_{3} E_{G} \\
W_{G} & =W_{1}+W_{2}+W_{3}+\left(v_{G}-v_{1}-v_{2}-v_{3}\right) E_{G}
\end{aligned}
$$

Total revenues are the cost of the upstream and downstream subsidy payments for a producer country: $T R_{i}=-\gamma_{i} Y_{i}-\eta_{i} x_{i}$. The external benefits are proportional to consumption of the product, and we allow different countries to have different global benefits from the environmental good: $E_{G}=\mu_{1} x_{1}+\mu_{2} x_{2}+\mu_{3} x_{3}$. For example, renewable energy use can displace emissions from fossil energy by factor $\mu_{i}$ in country $i$.

The strategic subsidy choice can be modeled as a two-stage game. In the first stage of the game, a region chooses whether and how much to subsidize downstream and upstream. We may think of this cost subsidy as the net effect of a range of policies, including direct subsidies, $R \& D$ support etc. ${ }^{8}$ In the second stage of the game, downstream demand is met, and the technology firms compete to supply renewable energy technology equipment to the downstream consumers in all regions.

We first solve for the optimal subsidy strategy from the point of view of a global planner. We then consider a Nash equilibrium, in which each region chooses optimal subsidies, given the choices of the others. We may also consider unilateral policies, assuming no subsidies in the other regions, or second-best subsidies, when trade rules, say, prohibit the use of either upstream or downstream subsidies.

We begin with the simplifying assumption that our two producing regions are symmetric. We will later relax this assumption to explore asymmetry numerically. All the solutions can be derived algebraically, and for convenience we do this in Mathematica and report only the results; more details are given in the Appendix, and files are available upon request. Knowing the market equilibrium response to subsidies, each actor maximizes welfare with respect to the policy levers it controls, upstream and/or downstream subsidies in the producing states, taking as given the policy choices in the other region.

Specifically, the global planner would maximize global welfare with respect to choosing upstream and downstream subsidies in each producing region. That is,

8 The welfare effects of R\&D support may be different from the effects of direct subsidies. This is disregarded in our welfare analysis below as we do not focus on innovation externalities. 
$\left\{\partial W_{G} / \partial \gamma_{1}=0, \partial W_{G} / \partial \eta_{1}=0, \partial W_{G} / \partial \gamma_{2}=0, \partial W_{G} / \partial \eta_{2}=0\right\}$. When effects are symmetric, we restrict the optimal subsidies to be symmetric, to allow better comparison to the noncooperative equilibrium. We also consider the cases in which either downstream or upstream subsidies are restricted to zero, implying the conditions $\left\{\partial W_{G} / \partial \gamma_{1}=0, \eta_{1}=0, \partial W_{G} / \partial \gamma_{2}=0, \eta_{2}=\eta_{1}\right\}$ or $\left\{\gamma_{1}=0, \partial W_{G} / \partial \eta_{1}=0, \gamma_{2}=0, \partial W_{G} / \partial \eta_{2}\right\}$.

In the Nash game, each producing country maximizes its own welfare, taking as given the subsidy choices of the other actor, and knowing the subsequent effects on the international market equilibrium. In equilibrium, $\left\{\partial W_{1} / \partial \gamma_{1}=0, \partial W_{1} / \partial \eta_{1}=0, \partial W_{2} / \partial \gamma_{2}=0, \partial W_{2} / \partial \eta_{2}=0\right\}$ all must hold. In the cases where subsidy choice is restricted either upstream or downstream, we consider $\left\{\partial W_{1} / \partial \gamma_{1}=0, \eta_{1}=0, \partial W_{2} / \partial \gamma_{2}=0, \eta_{2}=0\right\}$ and $\left\{\gamma_{1}=0, \partial W_{1} / \partial \eta_{1}=0, \gamma_{2}=0, \partial W_{2} / \partial \eta_{2}=0\right\}$.

\section{Market Failures}

We elaborate the three types of market failures: imperfect competition, downstream externalities, and external scale economies. All of our market failures lead to underprovision of the good, which can in theory be corrected by either upstream or downstream subsidies. It is important to make the distinction between these policy levers, since the strategic incentives differ, as do WTO disciplines. We also emphasize production and consumption subsidies together. The trade literature has more traditionally evaluated export subsidies, but for the case of renewable energy, the former are much more important in practice than the latter.

\section{Imperfect Competition}

We begin with the market failure of imperfect competition in the upstream market. As we consider identical products, we model the well-known case of Cournot competition. The analysis is similar to Brander and Spencer (1985) and Eaton and Grossman (1986), but we include consumption as well as production subsidies, allow for multiple firms within each country, and place a greater emphasis on the global welfare effects of internalizing the upstream market failure.

The Cournot framework is well suited not only for placing the results in context with the previous trade literature but also for representing the renewable energy technology industry. Wind turbine manufacturing is highly concentrated among a few major players, as previously noted. Pillai and McLaughlin (2013) observe that in the solar industry, although products are 
vertically differentiated by module efficiency, firm markups are positively associated with firm size, as would be implied by a Cournot model.

With Cournot competition, firms essentially compete by choosing production capacity, and this commitment ensures that any subsequent price competition allows for positive markups. Assume there are $N=n_{1}+n_{2}$ firms that are identical, save for the upstream subsidy policies of their countries. ${ }^{9}$ Total production is $Y=Y_{1}+Y_{2}=n_{1} y_{1}+n_{2} y_{2}$, and in the supply and demand equilibrium $P=A-B Y$. A firm country in $i$ maximizes profits, taking as given the output quantity choices of the other firms (at home and abroad) and any subsidy $\gamma_{i}$ it is offered:

$$
\pi_{i}=\left(A-B\left(y_{i}+Y_{-i}\right)-c+\gamma_{i}\right) y_{i}
$$

The first-order condition has marginal revenue equal to marginal cost:

$$
\frac{\partial \pi_{i}}{\partial y_{i}}=A-c+\gamma_{i}-B\left(Y+y_{i}\right)=P-B y_{i}-c+\gamma_{i}=0
$$

Let $\bar{\gamma}=\left(n_{1} \gamma_{1}+n_{2} \gamma_{2}\right) / N$. From the first-order conditions and the above demand function, we have equilibrium output of a firm in each country and overall:

$$
y_{d}=\frac{A-c+\gamma_{d}+N\left(\gamma_{d}-\bar{\gamma}\right)}{B(N+1)} ; \quad Y^{C}=\frac{N(A-c+\bar{\gamma})}{B(N+1)}
$$

And the equilibrium price, which includes a cost markup

$$
P^{C}=c-\bar{\gamma}+\frac{A-c+\bar{\gamma}}{N+1}
$$

At the social optimum, absent any other market failures, we would have $P=c$ in all jurisdictions and $Y^{C^{*}}=(A-c) / B$. In theory, this result could be achieved with downstream and/or upstream subsidies; however, if the planner is restricted from setting downstream subsidies in the third region, then the optimal subsidies would be upstream and satisfy $\bar{\gamma}^{*}=(\bar{a}-c) / N$. The more concentrated is the industry (smaller $N$ ), the greater the underprovision and the higher the correcting subsidy. Note that since costs are identical, the

\footnotetext{
${ }^{9}$ Firm asymmetry has been explored in de Meza (1986) and Neary (1994). We will allow for country-level asymmetries. As discussed in Eaton and Grossman (1986), two studies-Horstmann and Markusen (1986) and Venables (1985) - analyze the effects of trade policy with free entry for the case of Cournot competition.
} 
planner does not care where production (or subsidizing) occurs; for ease of comparison, we will assume subsidies are applied symmetrically.

To explore the different incentives for individual regions and compare them with those of the planner, we derive the analytical results for symmetric producer countries (as in Brander and Spencer 1985, but with multiple firms), and report them in the Appendix. (In subsequent simulations we will allow for asymmetries across regions.) Solving for the optimal subsidies, we prove the following results when the upstream market competes in Cournot fashion:

Proposition 1(a): In the Nash equilibrium, strategic countries subsidize both upstream and downstream, while the social planner subsidizes only upstream.

As discussed above, the market failure of imperfect competition is an upstream one, so the planner finds upstream subsidies sufficient to internalize it. Strategic countries, however, recognize that the upstream subsidy depresses the market price for foreign sales, so they use some downstream subsidies to help support the global price and boost their terms of trade, while internalizing the market failure for their own consumers.

Proposition 1(b): To the extent that the third country has downstream market share, the sum of the Nash subsidies are less than the planner's subsidy.

The larger is the third country share, the more that strategic countries shift their subsidies downstream and underprovide them overall, since the downstream subsidy is less efficient at counteracting the upstream market failure. We also show that the more competition there is upstream (more firms), the smaller the subsidies, and the smaller the share of upstream subsidies in the Nash equilibrium.

Proposition 1(c): In the absence of a third-country market, the Nash equilibrium replicates the social optimum.

With no third-country market, strategic countries do not subsidize downstream; since the producers together are no longer net exporters, downstream subsidies do not influence the terms of trade (or rather they benefit upstream producers equally). Upstream subsidies are used to internalize the upstream market failure, and in the Nash equilibrium the average of the upstream subsidies converges to the planner's upstream subsidy. With asymmetric regions, the net importer contributes a higher upstream subsidy than the net exporter. 
Proposition 1(d): Maximizing the joint welfare of the producer countries requires an upstream tax and a downstream subsidy.

If the producer regions could collude to maximize their joint welfare, not only would they want to restrict the use of upstream subsidies, but they would want to tax their production and subsidize consumption to a greater extent than in the Nash equilibrium, since both activities improve the terms of trade.

The next propositions consider the results when the parties are restricted (such as by international trade law) from implementing certain types of subsidies.

Proposition 2(a): If the downstream subsidy is not available, producer countries underprovide upstream subsidies to a greater extent.

Without the downstream subsidy to prop up the global technology price, strategic countries use smaller upstream subsidies than in the dual-policy Nash equilibrium. Furthermore, the subsidies are even lower to the extent that the third country has downstream market share, since producers want to protect their terms of trade and, unlike the global planner, are not concerned with the welfare of third-party consumers.

Proposition 2(b): If the upstream subsidy is not available, producer countries underprovide downstream subsidies to the extent they have downstream market share.

Without the upstream policy tool, the globally optimal downstream subsidies in the producer countries are positive, but less than the optimal upstream subsidy, given that they are a second-best instrument for counteracting the upstream market failure. Furthermore, strategic countries provide even smaller downstream subsidies, since part of the effect is to bid up the global price for their own consumers. However, if the entire technology market is for export to the third country, strategic countries provide the globally second-best downstream subsidies.

Thus, if the upstream market is characterized by Cournot competition, there is no clear need in this partial equilibrium model for restrictions on production subsidies. The emphasis on global welfare is important. For example, Brander and Spencer (1985) look at the case of Cournot countries with production subsidies and emphasize that producing countries would be jointly better off with lower subsidies (similar to our Proposition 1(d)); however, they do not note that global welfare would be higher with higher subsidies. In essence, based on these kinds of models, an argument for trade law restrictions on upstream subsidies is facilitating collusion in the upstream market, not improving global welfare. 


\section{Downstream Externalities}

Let us now focus on the downstream external effects. To do so, we consider optimal policy responses as the upstream market failure goes to zero.

\section{Strategic Subsidies without Environmental Benefits}

As the market becomes perfectly competitive, in the absence of another market failure, not only do the optimal subsidies go to zero, but so do the strategic subsidies, since there are no excess profits to capture.

Proposition 3: As $N \rightarrow \infty$, without environmental benefits, $\gamma_{i}^{*} \rightarrow 0$, as do $\gamma_{i, v_{i}=0}^{\text {Nash }}$ and $\eta_{i, v_{i}=0}^{\text {Nash }}$.

\section{Strategic Subsidies with Environmental Benefits}

Now suppose that the consumption of the product downstream has an external benefit of $v_{G}$ per unit, as in the case of an environmental good. Again, with this market failure, we have underprovision in the absence of subsidies. At the social optimum, the price should equal the marginal social cost in each downstream country: $P_{D, i}{ }^{*}=c-v_{G} \mu_{i}$. Since the externality is downstream, this would suggest implementing the subsidies downstream $\left(\eta_{i}^{*}=\mu_{i} v_{G}, \forall i\right)$. However, in the presence of a third-party country that does not have these policy levers at its disposal, the optimum cannot be achieved with downstream subsidies alone. If the marginal benefits of the good are equal across all countries $\left(\mu_{i}=\mu, \forall i\right)$, then upstream subsidies of $\gamma_{1}^{*}=\gamma_{2}^{*}=v_{G} \bar{\mu}$ alone suffice to achieve the optimum. But when marginal benefits differ, a combination of up- and downstream subsidies is needed to maximize welfare.

Proposition 4: As $N \rightarrow \infty$, the globally optimal policy is to subsidize upstream at the rate of the third-country marginal benefit, and to subsidize consumption in the producer countries according to the difference in the marginal benefit from that of the third country: $\left\{\gamma_{1}^{*}=\gamma_{2}^{*}=\gamma^{*}=v_{G} \mu_{3} ; \eta_{i}^{*}=v_{G}\left(\mu_{i}-\mu_{3}\right)\right\}, i=\{1,2\}$.

With an external environmental benefit from downstream consumption, the planner wants the total subsidy in each country to equal the social marginal benefit; that is, $\gamma^{*}+\eta_{i}^{*}=v_{G} \mu_{i}, \forall i$. If subsidies cannot be implemented in the third-party country, the optimal strategy is to use the uniform upstream subsidy to reflect the third-country's external benefit, while downstream subsidies (or taxes) are used in the producer countries to adjust net subsidy. 
Proposition 5(a): In the Nash equilibrium, moving toward perfect competition $(N \rightarrow \infty)$, upstream production subsidies become negligible $\left(\gamma_{i}^{\text {Nash }} \rightarrow 0, i=\{1,2\}\right)$, and downstream consumption subsidies converge to the marginal benefit as valued by that country: $\eta_{i}^{\text {Nash }} \rightarrow v_{i} \mu_{i}, i=\{1,2\}$.

Proposition 5(b): Without a third country, in a Nash equilibrium, the noncooperative subsidies replicate the social optimum if each country values environmental changes at the global marginal benefit.

This follows from Proposition 1(c), which notes that without a third-country market, the producer countries on average do not want to distort the terms of trade. Thus, if $v_{i}=v_{G}$, since well, then both market failures will be internalized. The producers combine upstream and downstream subsidies in such a way that the total subsidies equal those desired by the planner for each region, assuming the countries adopt the global valuation of the externality. In this case, the planner is indifferent as to where to target the subsidies, since only the sum matters.

Proposition 5(c): With a third country, a symmetric Nash equilibrium provides insufficient upstream subsidies and lower environmental gains to the extent that $\mu_{3}>0$, even if $v_{i}=v_{G}$.

Although strategic countries may care about leakage, the incentive to maintain higher export prices remains, resulting in global underprovision of the green good. This underprovision is further exacerbated to the extent that global gains are undervalued locally.

Thus, downstream external benefits provide another situation in which strategic upstream subsidies may be too low from a global welfare perspective.

\section{External Scale Economies}

With scale effects - such as through learning-by-doing, supply chain effects, or network economies - unit costs of production may depend on cumulative industry output. To the extent that these effects spill over to other firms and the benefits are not fully appropriated by the individual actors, scale will be underprovided by the market. To explore the role of spillovers from scale effects, we assume that marginal costs are influenced by own and foreign scale of production. Although some of these processes may be dynamic, let us represent them in condensed form by shifting marginal production costs according to cumulative market scale in our static model. 
Let marginal production costs be a decreasing function of total industry (domestic and foreign) scale: that is, $c_{0}-g Y .{ }^{10}$ Thus, a domestic producer's profits are

$$
\pi_{i}^{d}=\left(A-B\left(y_{i}^{d}+Y_{-i}^{d}+Y_{f}\right)+\gamma_{d}-c_{0}+g\left(y_{i}^{d}+Y_{-i}^{d}+Y_{f}\right)\right) y_{d}
$$

In the competitive equilibrium we have $n_{j} y_{i}^{j}=Y_{j}$ for each region $j$. The first-order condition for the individual domestic producer is

$$
\begin{aligned}
\frac{\partial \pi_{d}}{\partial y_{d}} & =A-c_{0}+\gamma_{d}-(B-g)\left(y_{d}\left(n_{d}+1\right)+n_{f} y_{f}\right) \\
& =P-c_{0}+g Y+\gamma_{d}-(B-g) y_{d}
\end{aligned}
$$

Adding the first-order conditions for all producers in both regions and solving for $Y$ gives

$$
Y=\frac{N\left(A-c_{0}+\bar{\gamma}\right)}{(N+1)(B-g)}
$$

To better compare the case of scale economies with that of imperfect competition alone, we want to consider cost parameters such that the baseline no-policy supply is the same as that without the assumption of scale effects. That is, for $Y^{N P}=\frac{N\left(a-c_{0}\right)}{(N+1)(B-g)}=\frac{N(a-c)}{(N+1) B}$, we need

$$
c_{0}=c+(a-c) g / B \text {. }
$$

Furthermore, we restrict ourselves to the case of normally behaved supply responses and positive optimal subsidies, implying that the scale economies do not exceed half the slope of demand $(B>2 g)$. $^{11}$

To focus on the effects of scale economies, let us assume there is no downstream environmental externality. Now we can compare the effect of scale economies on optimal subsidies. (All proofs appear in the Appendix).

\footnotetext{
10 Assuming full spillovers maintains the assumption of identical costs across firms and leads to a symmetric optimal policy. Incomplete international spillovers results in asymmetric cost effects and an optimal strategy that could target one region or another for upstream support and increase the market share of the lower-cost provider.

${ }^{11}$ See proof of Proposition 6.
} 
Proposition 6: With external scale effects, the globally optimal policy is to offer upstream subsidies that are higher than with imperfect competition alone and to offer no downstream subsidies.

Upstream subsidies are best suited to internalize the twin upstream market failures: spillover effects from the scale economies and underprovision by Cournot competitors. Because spillovers represent an additional market failure, the optimal subsidy is higher. Note that optimal policy is not influenced by market shares, since all producers have the same costs.

The strategic Nash equilibrium, on the other hand, is influenced by the upstream and downstream market shares of the producing countries. To avoid excessive complications and keep the focus on the scale effects, let us consider the equilibrium with symmetric producing countries.

Proposition 7(a): In the symmetric Nash equilibrium, strategic countries subsidize both downstream and upstream, and the presence of scale effects lowers that sum.

As in the other market failure examples, strategic countries want to maintain higher prices for their net exports. What is interesting is that although scale effects increase the optimal subsidy, they lower the total strategic subsidies. This result is not dependent on the third-party market share (although it does influence the magnitude); rather, it reflects the spillover effects and incentives to free-ride on the cost reductions made by the other's investment in scale.

Proposition 7(b): With scale economies, symmetric strategic countries offer total subsidies that are less than those desired by the global planner, even in the absence of a third-party downstream market.

This result follows from Proposition 7(a) and stands in contrast to Proposition 1(c): with imperfect competition as the only market failure, producers replicate the optimum in the absence of the third-party market. Here, scale economies with global spillovers create incentives to underinvest in capacity, since part of the benefits accrue to the other party.

Thus, if the upstream market is characterized by external scale economies, there is no clear need in this partial equilibrium model for restrictions on upstream production subsidies. Countries tend to prefer downstream subsidies to maintain higher global prices for their exports and enjoy the spillover benefits of overall market scale. 


\section{Combining Market Failures: An Application to Renewable Energy}

The theoretical analysis draws intuition for situations in which strategic trade partners may underprovide production subsidies in the presence of market failures. In this section, we explore these results quantitatively in a parameterized application to the renewable energy technology sector.

\section{Numerical Model}

We represent the producer-consumer regions of Europe, the United States, and China, since well as consumption in the rest of the world (ROW). Each region has a downstream market for electricity generation that is closed to international trade (this framework could be applied equally to renewable fuels in transportation). The downstream markets consist of firms located and owned in the corresponding regions, and competition is perfect. ${ }^{12}$ Electricity generation with conventional fossil-fueled technology leads to emissions of a pollutant that may have crossborder damages (e.g., $\mathrm{CO}_{2}$ ). An alternative energy technology, such as solar panels or wind turbines, can produce electricity without emissions.

To calibrate the linear technology demand functions and the emissions consequences, we use simplified static versions of the calibrated electricity sector models in Fischer et al. (2013) for the United States and Hübler et al. (2016) for the European Union. ${ }^{13}$

The data represent annual electricity production in a near-term horizon of 2015-2020. The downstream electricity market is composed of energy supply curves from coal, oil, natural gas, nuclear, hydro, and non-hydro renewables. The latter are our focus, and they include wind, biomass, solar, and others like geothermal, with wind being the dominant source. These renewables represent 17 percent of EU electricity demand and 7 percent of US demand. All supply sources, as well as consumer demand, respond to changes in electricity and carbon prices. We back out from the system the implied demand for renewable energy capacity, as well as the emissions consequences. For example, in the baseline, the average emissions of non-baseload nonrenewable energy sources (essentially coal and gas, since the capacity of nuclear and hydro is fixed) are 13 percent higher in the United States; however, when we calculate the marginal

\footnotetext{
12 The primary assumption is that the fossil supply curve is upward sloping and cost increases are fully passed through. This assumption is less realistic for China, where prices are regulated and adjusted infrequently.

13 These models were designed for looking at endogenous technical change across two stages; to create a static model, we use the first stage only.
} 
emissions rates from these sources in response to a small price change, they are twice as high in the United States as in the European Union.

For China and ROW, we use the supply mix projected for 2020 in the International Energy Outlook 2013 (EIA 2013), depicted in Figure 1. Lacking comparable data to calibrate their cost functions directly, as has been done for the United States and the European Union, we calibrate the slopes of the supply curves to match the same supply elasticities as in the United States, as China and ROW are more similar in their energy mix to the United States than the European Union, which is by far the least fossil-fuel dependent. We note that by 2020, while the EU and US electricity markets are projected to be similar in size, the Chinese power sector will be nearly twice as large, and ROW's almost four times as large.

Figure 1. Projected Baseline 2020 Energy Mix, by Region

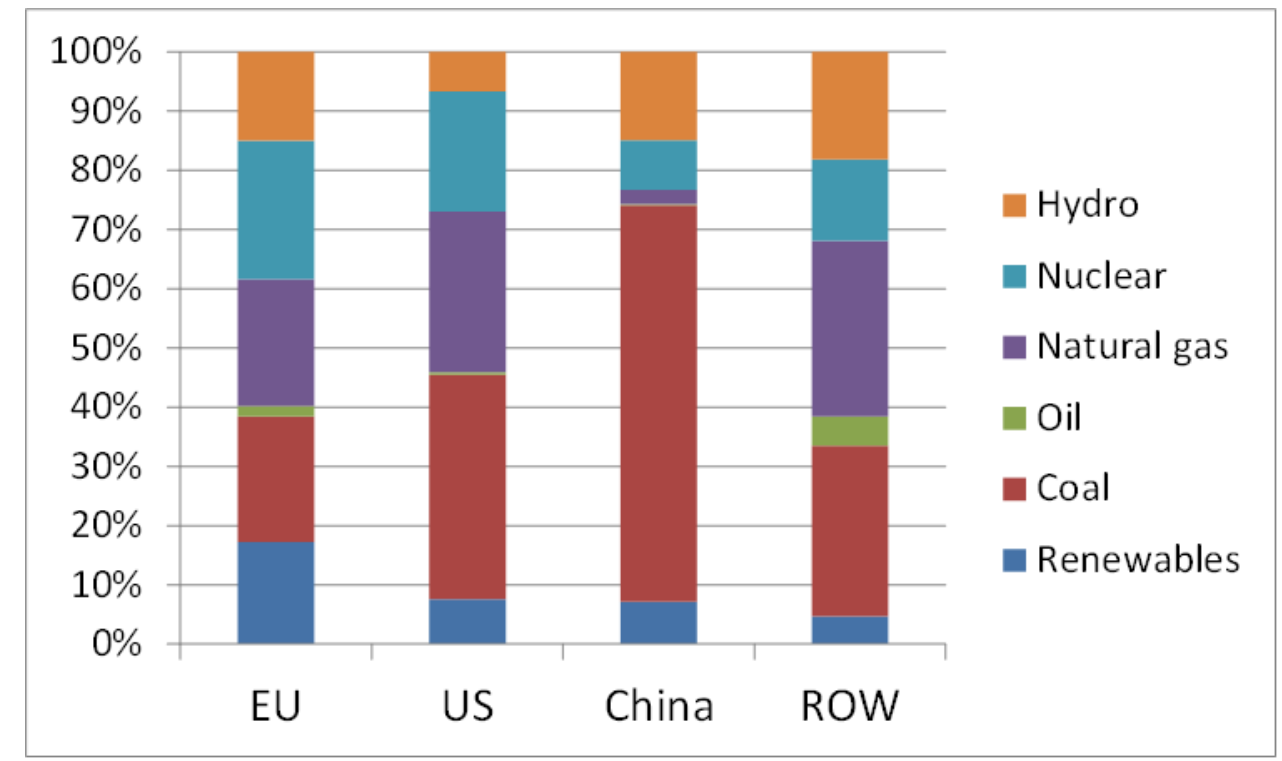

(Source: EIA 2013)

Downstream outcomes, including the resulting demand for renewable energy, depend importantly on the downstream policy assumptions. We incorporate a downstream carbon price $\tau_{i}$ that varies across regions, as well as a downstream subsidy to renewable energy. ROW is always assumed to have no policy. For example, for the European Union and the United States, the calibrated downstream model calculates the following renewable energy demand functions:

$$
\begin{aligned}
& x_{E U}=6.04 \times 10^{11}+1.43 \times 10^{9} \tau_{E U}+3.65 \times 10^{12}\left(P+\eta_{E U}-P_{0}\right) \\
& x_{U S}=2.99 \times 10^{11}+5.06 \times 10^{9} \tau_{U S}+5.32 \times 10^{12}\left(P+\eta_{U S}-P_{0}\right)
\end{aligned}
$$

where $P_{0}$ is the global technology price in a baseline without subsidies. 
For the upstream market, we draw on the wind turbine manufacturing sector, where the top four producers of wind turbines (located in the United States and Europe) supply roughly half the global market; from the top 10 producers, 70 percent of global production occurs in the United States (16 percent), Europe (38 percent), and China (17 percent). For this first series of simulations, we focus on the United States and Europe (REN21). The top two producers, GE from the United States and Vestas from Denmark, had 15.5 percent and 14 percent market shares, respectively, in 2012. In a Cournot model, these kinds of market shares occur when there about 7 firms; we round up to allocate 2 firms each to the United States and China and 4 to Europe, to maintain roughly the correct producer market shares in our representation of imperfect competition. Since we perform sensitivity analysis to the degree of competition, in scenarios with "perfect competition" we will scale up firm numbers by a factor of 100 , maintaining similar overall market shares. ${ }^{14}$

To consider cost and scale effects, we assume that levelized technology costs per $\mathrm{kWh}$ generated in the baseline equal $c=0.045$, which is half the lowest baseline electricity price. ${ }^{15}$ In the absence of scale effects, this cost is fixed and its level has no effect on the results, since the downstream renewable generation supply functions are calibrated to replicate the baseline, with the intercepts adjusting one-for-one for the baseline input technology costs. We subsequently compare a situation havingwith no scale effects with one where a doubling of scale reduces costs by a third, relative to the baseline (i.e., $g=c / 3 / Y_{\text {Baseline }}$, and $c_{0}=c+(A-c) g / B$, where $A=0.0687+P_{0}$ and $B=3.1477 \times 10^{-14}$, as derived from the global downstream demand function). The baseline technology price, $P_{0}$, is subsequently calibrated to reproduce the baseline quantities, and depends on the number of firms and the baseline cost assumption. ${ }^{16}$

\footnotetext{
14 This is a reasonable approximation within the Cournot framework, and avoids having to introduce a new cost function as in the theory section.

15 This cost assumption is a rough estimate. Calculations by a consortium of industry experts in Europe found that wind turbines make up three-quarters of the installed cost of wind generation capacity (http://www.wind-energy-thefacts.org/index-43.html accessed 3/17/2016), and operation and maintenance represents $25 \%$ of levelized costs (http://www.wind-energy-the-facts.org/operation-and-maintenance-costs-of-wind-generated-power.html accessed 3/17/2016).

16 Any assumption about $c$ has a 1-1 effect on this price, and subsequently an offsetting effect on the estimated intercept of the marginal operating cost curve for renewable energy, which in the baseline must equal $P_{0}^{k W h}-P_{0}$.
} 


\section{Results}

In the following scenarios, we explore quantitatively the role of major factors identified in the theoretical analysis. One set involves the value of the social cost of carbon (SCC), its valuation by producer countries, and the pricing of carbon in downstream markets. These variations explore the sensitivity of the optimal subsidies to the downstream market failure and to preexisting downstream regulations. Another issue relates to downstream market shares, the size of the export market, and the importance of the nonproducing region. Third, we are interested in the degree of competition and scale economies, and to what extent upstream market failures drive subsidies. Finally, we assess the welfare and distributional consequences of optimal and strategic subsidies and restrictions on them.

\section{Carbon Externality and Trade}

We begin with a set of central assumptions: imperfect competition, no scale economies, and no other climate policies, although the countries do value emissions at the global SCC.

Figure 2 reports optimal and strategic Nash subsidies for the European Union as a function of the SCC when no region is taxing emissions. With no externality $(\mathrm{SCC}=0)$ and heterogeneous countries, the optimal upstream subsidy internalizes the upstream externality, here about 1 cent/kWh. The Nash strategy for the European Union has an upstream subsidy roughly half that size, paired with a small downstream subsidy that does not quite make up the difference. As the SCC rises, there is a clear and growing deviation between the strategic and optimal subsidies. The global planner would call for larger upstream subsidies - and downstream taxesas the SCC rises, since both strategies encourage more uptake of renewables and displacement of polluting outside the relatively clean European Union.

For an SCC of $\$ 30$, the optimal upstream subsidy is about 4 cents $/ \mathrm{kWh}$, reflecting the value of the downstream eternality in ROW. The European Union, on the other hand, does raise its upstream subsidy as the SCC rises, but less than is optimal, preferring to supplement with more downstream subsidies. Figure 3 shows the effective total subsidies $\left(\bar{\gamma}+\eta_{i}\right)$ for each region under optimal (“*”) and strategic policies, reported for the central assumptions. The European Union, having the least-emissions-intensive electricity sector to start, has significantly lower optimal net subsidies than the others, of which China, being the most coal reliant, has the highest. Note that for the producer regions, the sums of the subsidies are quite similar in both the optimal and the strategic cases; they rise accordingly with the SCC, as predicted in the theory (Proposition 5(a)), and the difference is due to the response to imperfect competition, which strategic countries underinternalize (Proposition 1(b)). The large difference is for ROW, where 
the optimal total subsidy is much higher than the average upstream subsidy provided by strategic regions, and the difference grows larger as the SCC increases.

Figure 2. Optimal and Strategic Subsidies in the European Union as Function of SCC (with Imperfect Competition, No Scale Economies, No Carbon Taxes)

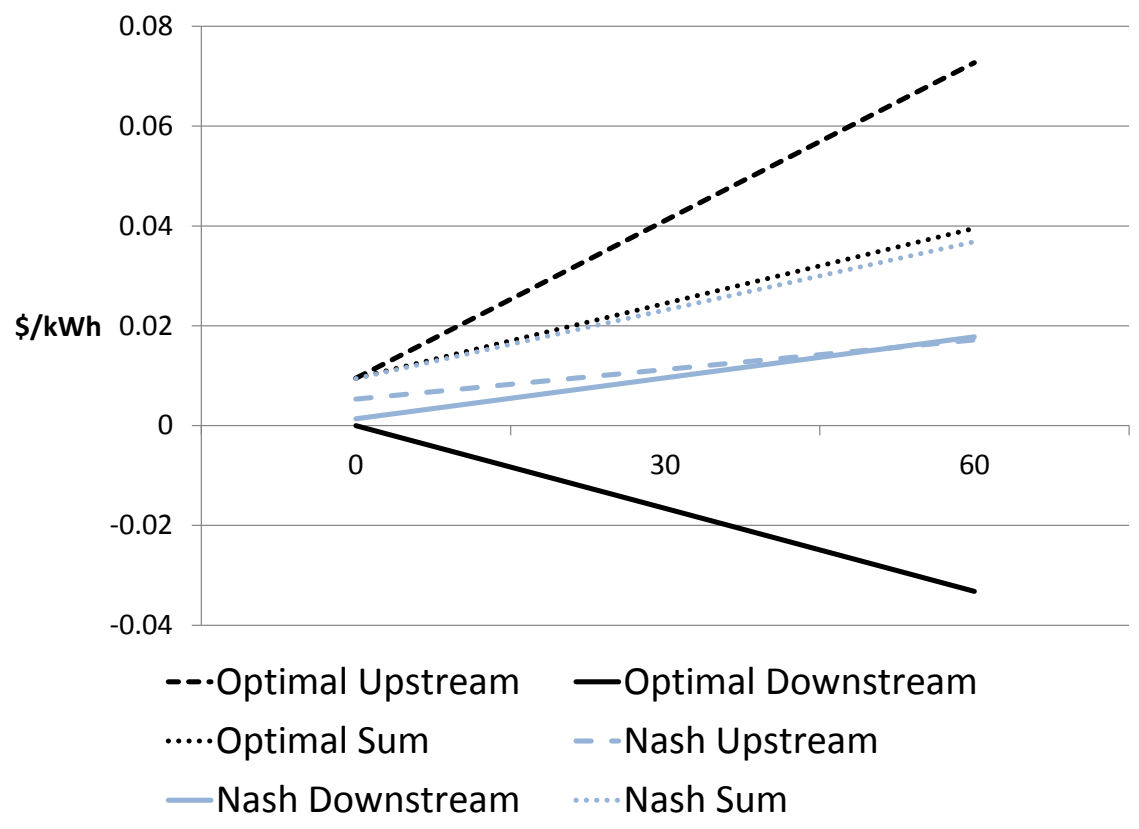

Figure 3. Optimal and Strategic Net Subsidies as Function of SCC (with Imperfect Competition, No Scale Economies, No Carbon Taxes)

0.12

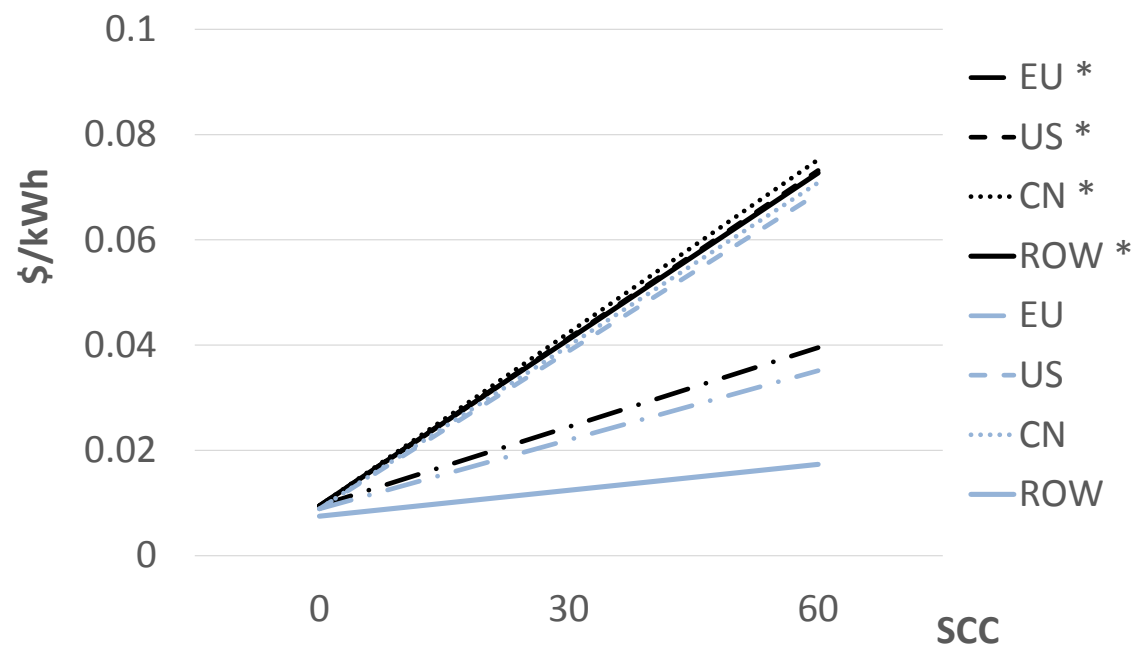


These subsidies all assume no carbon pricing. In fact, as long as ROW does not tax carbon, optimal and strategic upstream subsidies do not depend on whether any other region taxes carbon. The planner uses the upstream subsidy to internalize the upstream market failure and the downstream market failure in ROW, and the downstream subsidy is used to internalize the relative external costs in the producer countries (as in Proposition 4). Thus, if any producer region taxes carbon at the SCC, the optimal subsidy in that region falls.

Similarly, the choice of subsidy by strategic regions is not influenced by other regions' carbon-pricing behavior, but their own downstream subsidies fall when they choose to internalize the carbon externality with a tax at home. ${ }^{17}$ These effects are illustrated in Figure 4.

Figure 4. Optimal $\left(^{*}\right)$ and Strategic (N) Subsidies as Function of Regional Carbon Pricing (Imperfect Competition, No Scale Economies)

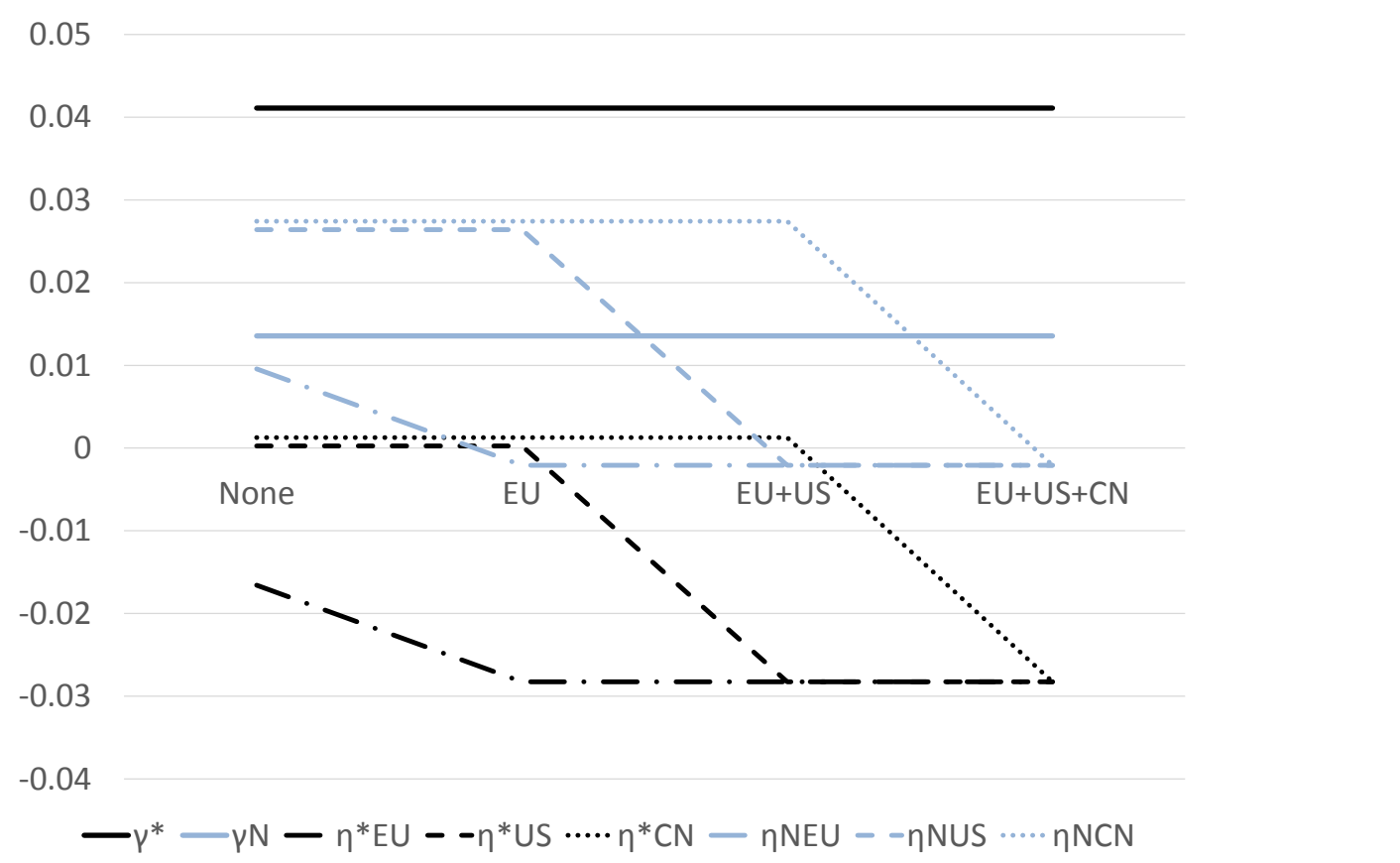

\footnotetext{
${ }^{17}$ With scale economies, downstream subsidies for regions with carbon pricing will diverge somewhat because of the differences in scale-related spillovers.
} 


\section{Role of ROW and Exports in Strategies}

Figure 5 depicts the difference in optimal and strategic outcomes for deployment and production of renewable energy technologies, assuming an SCC of \$30 but no carbon taxes. Note that in both cases the European Union experiences little change in renewable energy deployment, but the other regions increase deployment substantially. Note also that in all the producer countries, there is no difference in the deployment outcomes between the optimal and Nash strategies. The difference lies in ROW, where the global planner's greater reliance on upstream subsidies leads to much greater deployment than the Nash outcome, where producers prefer higher global technology prices.

The strategies have different producer country effects as well. The optimal subsidy policy maintains the baseline market shares (50 percent for the European Union, 25 percent each for the United States and China). The Nash equilibrium, however, shifts production away from Europe, a large net exporter, toward China, which is a larger consumer nation and, as a smaller net exporter, has less interest in withholding production to keep global prices high.

\section{External Scale Effects and Competition}

The effects of scale economies are revealed in higher optimal net subsidies to offset the additional upstream market failure. Figure 6 replicates Figure 3 but with the inclusion of scale economies. In the absence of an environmental externality, the optimal subsidy has risen to 4 cents/kWh, 3 cents higher than without scale economies, and that premium grows along with the SCC. The market failure of scale economies also drives a larger wedge between the optimal and strategic sums of the subsidies for the producer regions, as predicted in the theory (Proposition 7(a)). And although scale economies increase the optimal upstream subsidies (the net subsidies for ROW), they decrease the average upstream subsidies provided in the Nash equilibrium. 
Figure 5. Deployment and Supply, by Scenario (billions of kWh annual generation)
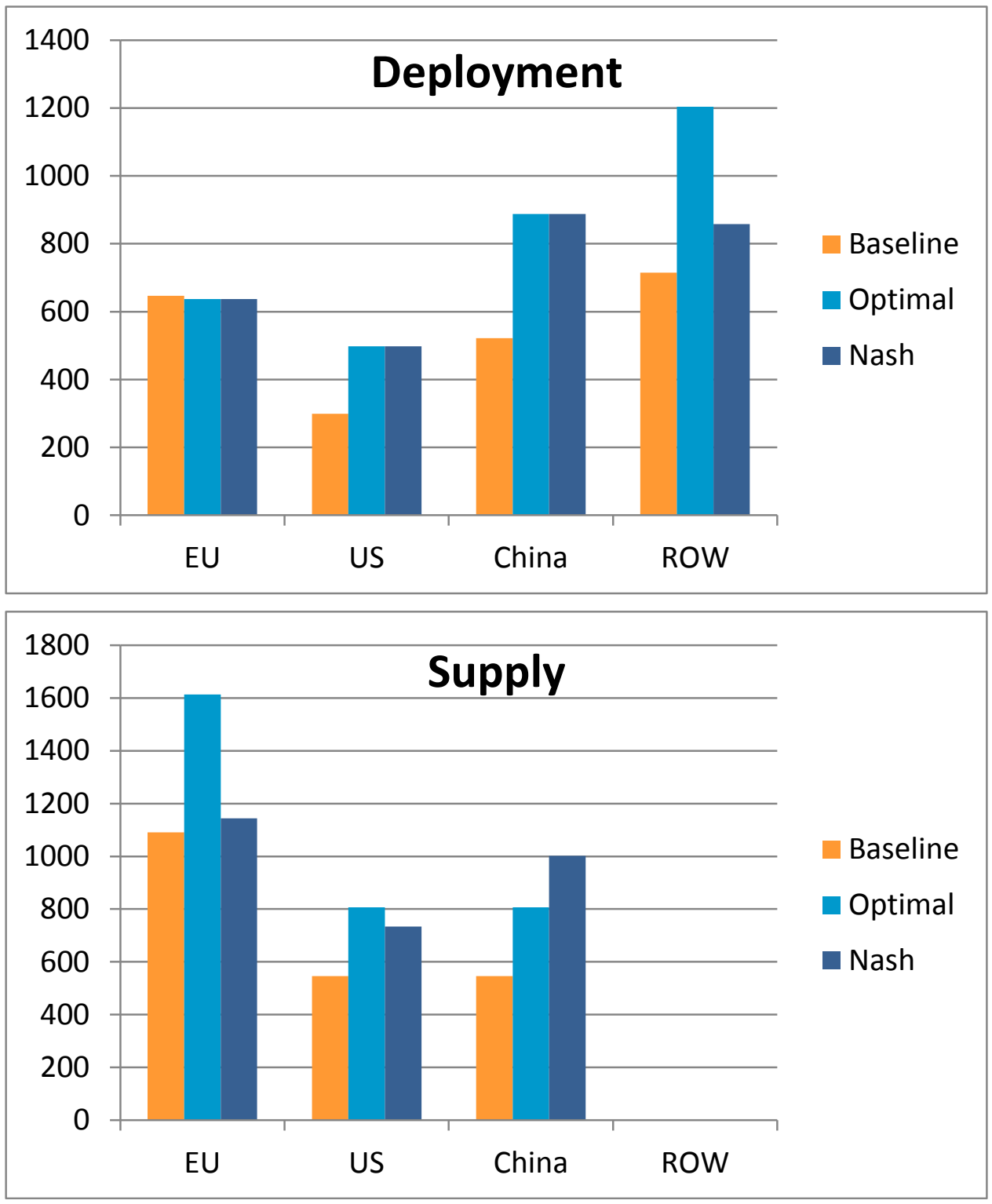
Figure 6. Optimal and Strategic Net Subsidies with Scale Economies as Function of SCC (No Carbon Taxes)

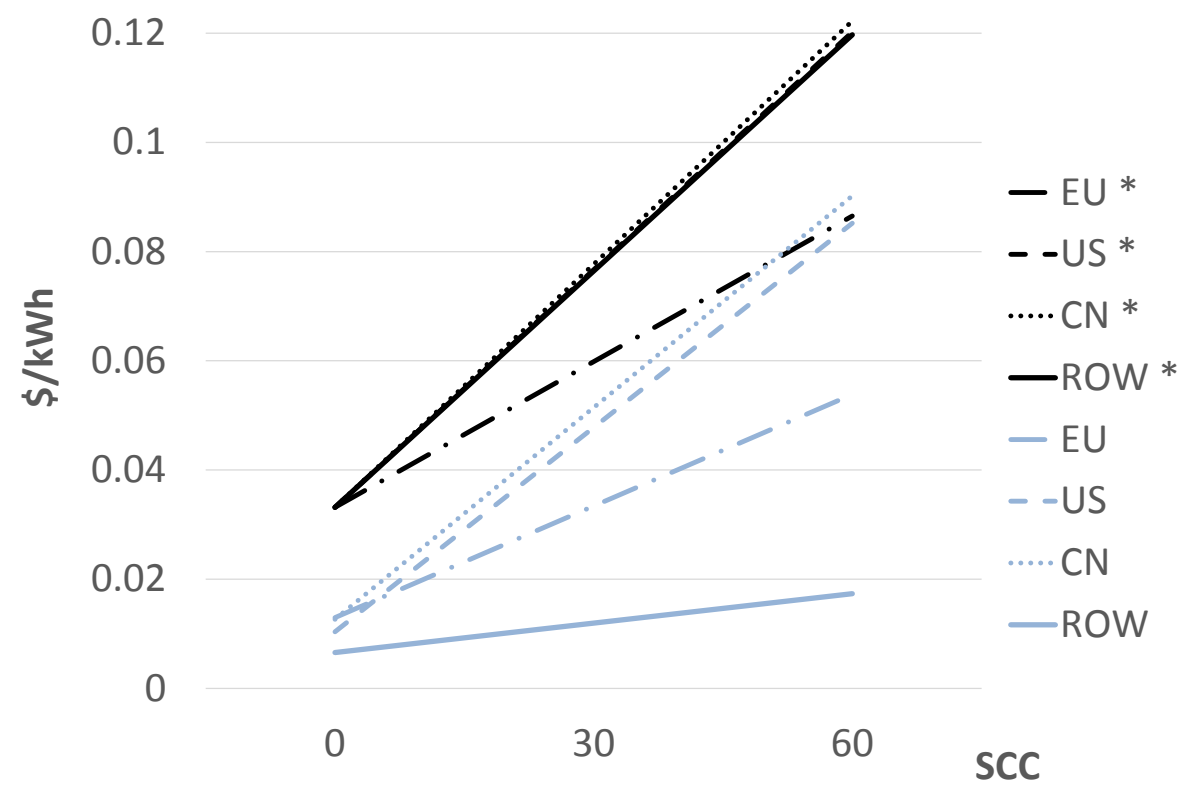

Scale economies, as modeled, interact with the degree of competition. In the scenario of "perfect competition" ( $N=800$ instead of 8$)$, optimal and Nash subsidies are negligible in the absence of an environmental externality. Strategic downstream subsidies in the producer countries equal the optimal net subsidies for those countries (as in Proposition 5(a)). With scale economies, however, optimal upstream subsidies are 2 cents/kWh when $\mathrm{SCC}=0$, compared with 4 cents with imperfect competition (and 1 cent with imperfect competition alone, without scale effects). Strategic countries with competitive firms do not subsidize upstream, but with scale economies they do subsidize downstream at about 0.5 cents/kWh or less when $\mathrm{SCC}=0$, thus internalizing roughly a quarter of the externality for the producer countries but achieving less global scale than with a comparable upstream subsidy that would also apply to ROW demand.

\section{Welfare Effects of Restrictions on Subsidies}

How do strategic subsidies and trade law constraints on them affect welfare in a situation of market failures? Figure 7 considers the case in which we have imperfect competition and the SCC is $\$ 30$. To get a sense of the scale of the benefits of intervention, with the central assumptions, implementing that SCC as a global carbon price (including ROW) would reap \$60 
billion in gains annually in the electricity sector. The vast majority of that improvement comes from the global nature of the carbon tax; one loses only 3 percent of this welfare improvement by eliminating the optimal subsidy for counteracting imperfect competition upstream. ${ }^{18}$ By contrast, if ROW does not implement carbon pricing, only 39 percent of the potential welfare gains from the optimal mix would be captured. Thus, the carbon leakage externality is far more important than the problem of imperfect competition.

For this reason, we next observe that optimal subsidies become close substitutes for incomplete carbon pricing. On their own, optimal subsidies implemented in the producer countries can generate a $\$ 20$ billion improvement, almost as much as a carbon tax implemented only in the producer countries, and nearly twice the gains of a carbon price applied only to the European Union and the United States. The Nash equilibrium of strategic subsidies is somewhat smaller but still achieves nearly $\$ 15$ billion in global economic and environmental improvements. It may be surprising that renewable energy subsidies can be nearly as effective as carbon pricing among this coalition, since one loses the margin to switch among other fossil fuel sources. This option turns out not to be that valuable: half of global electricity demand is in ROW, which would not face a carbon price, and half of electricity demand facing the carbon tax is in China, where natural gas plays a very small role. Meanwhile, carbon leakage is very important, and renewable energy subsidies are the only policy option for addressing that.

Now consider the effects of restrictions. If upstream subsidies are made unavailable, as represented by the Nash equilibrium with only downstream subsidies, the benefits fall to less than $\$ 10$ billion. It may be interesting to note that, although not depicted, the benefits of a carbon tax that is restricted to the European Union and the United States are not much more than those of Nash downstream subsidies alone. Finally, if we limit interventions to downstream subsidies in just the European Union and the United States, the benefits are negligible, since they draw resources away from the rest of the world, where deployment has more value in reducing emissions.

\footnotetext{
18 If SCC $=0$, the gains from optimal policy (an upstream subsidy) are even smaller, just \$1 billion annually, but the costs of restricting upstream subsidies remain similar in relative terms to the optimal policy combination.
} 
Figure 7. Change in Welfare from No Policy; All Regions Value Emissions at SCC of $\$ 30 /$ ton $\mathrm{CO}_{2}$ (Central Assumptions of Imperfect Competition and No Scale Effects)

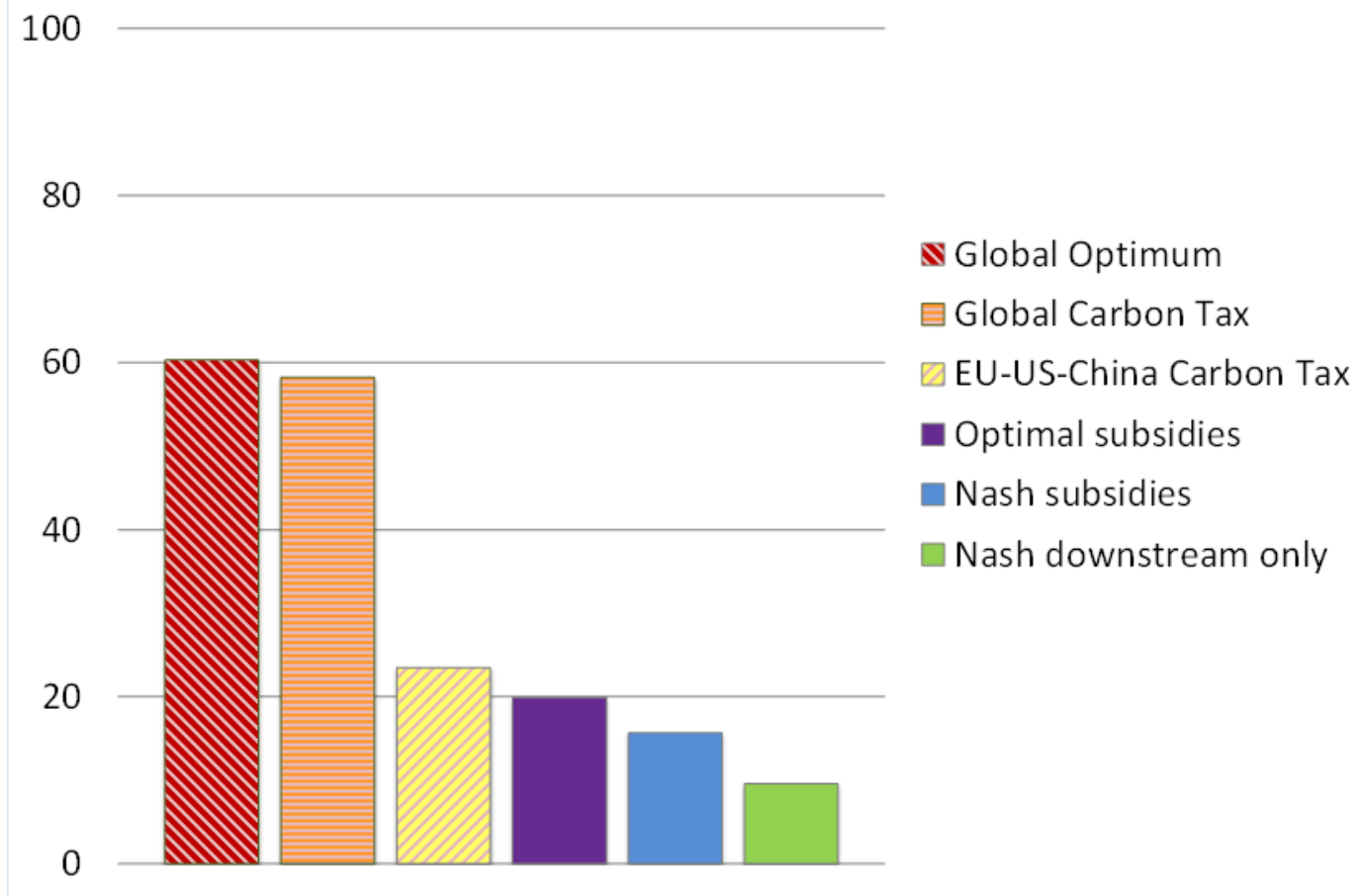

The presence of scale economies has important implications for the absolute and relative welfare effects of the policies, as visualized in Figure 8. As renewables become significantly cheaper, deployment expands and the welfare gains are much larger across the board, and nearly double in the optimal policy scenario. The loss of upstream subsidies from the optimal policy mix is much more costly because of the presence of spillovers: 25 percent of the potential gains are lost when a global carbon tax is implemented alone.19 With the twin market failures of imperfect competition and scale economies, optimal subsidies now not only outperform carbon taxation among the producer countries but deliver nearly twice the gains. Strategic subsidies are less effective but still allow for more gains than carbon pricing alone in the producer regions.

\footnotetext{
19 The carbon tax here is fixed at the SCC; we do not adjust to a second-best level.
} 
Figure 8. Change in Welfare from No Policy with Scale Effects (with Imperfect Competition, All Regions Value at SCC of $\$ 30 /$ ton $\mathrm{CO}_{2}$ )

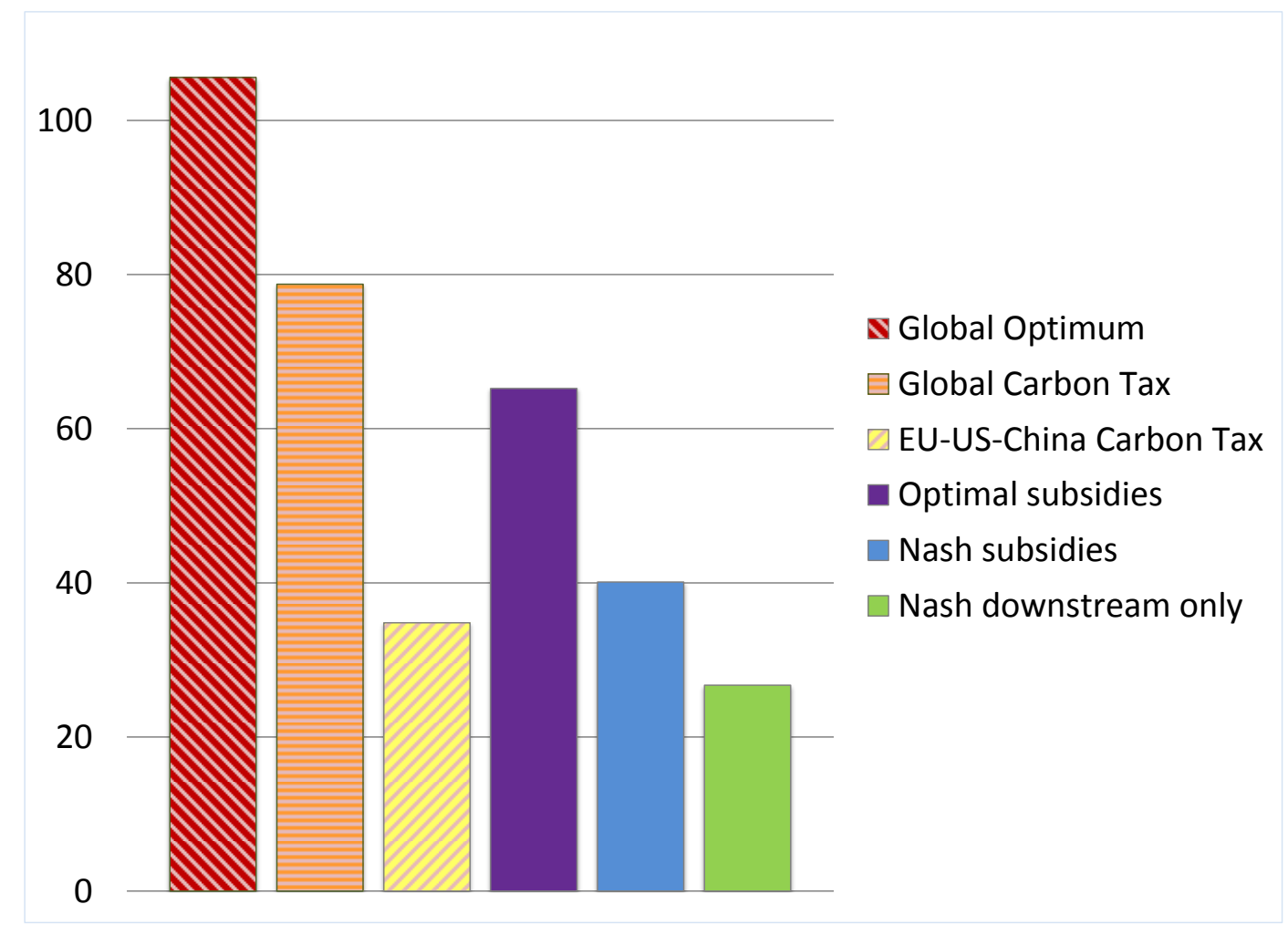

An important question is whether downstream subsidies can produce scale effects that make up for the loss of downstream subsidies. The results indicate that restricting the use of upstream subsidies is somewhat less costly in relative terms when there are scale effects: Nash downstream subsidies yield 24 percent of optimal gains with scale effects, compared with only 15 percent without them. However, in absolute terms, the magnitude of the potential gains forgone is much larger.

The distributional effects of the policies are quite different as well. The globally optimal subsidies involve large transfers from producer to consumer countries, and more so from the European Union, the largest net exporter and a region where consumption is discouraged by a downstream tax. Nash subsidies actually cost producer countries, compared with no subsidies, while benefiting ROW and to some extent China, a net importer of renewable energy technology. Without upstream subsidies, producer countries are better off, but the environment and ROW are worse off. Without scale economies, the environmental gains are larger with a carbon tax among producer countries than with optimal subsidies, but when scale economies are present, optimal subsidies reduce emissions more than the tax. 


\section{Conclusion}

This analysis has shown the importance of considering the global consequences of market failures when considering the value of market and trade interventions like subsidies - and the potential costs of placing restrictions on them. For products with concentrated markets, emerging technologies with scale effects, or green goods with global cross-border environmental benefits, underprovision may be a real problem. In these cases, subsidies can help correct the market failures. In particular, upstream subsidies_-by depressing global prices of the green good - tend to generate larger global benefits. However, it is these kinds of manufacturing subsidies that WTO rules tend to restrain. Although producer countries may benefit from these restrictions, global welfare is higher with strategic subsidy competition.

In the case of climate change, when constraints are put on carbon pricing (e.g., because of principles of common but differentiated responsibilities for developing countries or political resistance in developed countries), technology policies like subsidies become important secondbest tools. They are more effective to the extent they can reach all the major emitters, including developing and emerging economies, and toward that end, upstream interventions become relatively valuable. Furthermore, in the present framework, when regions maximize their own welfare, strategic subsidies do not overcompensate for the external effects; restrictions on upstream subsidies then become counterproductive.

Of course, governments may have their objectives distorted by interest group lobbying, as emphasized in the "protection for sale" literature launched by Grossman and Helpman (1994, 1995), leading to undesired protectionism. Fischer (2016) extends the present model to include an additional objective of promoting domestic industry scale, in which case allowing strategic upstream subsidies is very costly in global welfare terms unless external benefits are sufficiently high - or sufficiently undervalued. She also considers the alternative to upstream subsidies that the developed or producer countries could subsidize deployment in ROW (as with climate finance), but their strategic incentives to do so are significantly less, since they cannot guarantee that those subsidies would benefit their own producers, as they can with upstream subsidies.

Most of the analysis in this paper relies merely on the assumptions that global supply curves for the green good are upward sloping and that downstream demand for the good is downward sloping. Thus, the qualitative results should be robust to other frameworks. Although we have explored an application to renewable energy, the lessons should apply to a broad range of goods with spillover effects. For example, vaccines and therapies for communicable diseases can have global externalities as long as they remain under strict patent protection. 
The larger caveats to the conclusions relate to other, unmodeled rationales for which restrictions on manufacturing subsidies might be warranted. A deadweight loss from the taxation needed to fund subsidies makes them a more costly tool; however, national governments should internalize these costs, as would a global planner. In contrast, other market structure issues in which subsidies may lead to dynamic inefficiencies - like an ability to deter foreign entry and ultimately competition - are more likely to temper interest in loosening the restraints on industrial policy. ${ }^{20}$ Indeed, these allegations have been made recently in the case of solar panels. These issues are in addition to the problem of lobbying and rent seeking already mentioned.

Finally, several kinds of policies can have the effect of lowering upstream costs without direct subsidies to manufacturing and the related controversies. One example is regulatory policy that improves competition among suppliers, to address the distortions from market power. Another oft-used example is R\&D support, which can also address innovation spillovers and is rarely disputed internationally, although as a subsidy it is still not exempt from WTO scrutiny.

Given the many trade-offs regarding upstream interventions, more research is needed on the global effects of subsidies for green goods. Then a more thoughtful discussion can take place about whether and how to carve out appropriate legal space for such subsidies in international trade and environmental agreements.

${ }^{20}$ On the other hand, Dixit and Kyle (1985) show that although protection for domestic entry promotion is generally bad from a global standpoint, subsidies for entry promotion are more beneficial, and countermeasures against them ineffective or harmful. 


\section{References}

Alberici, S., S. Boeve, P. van Breevoort, Y. Deng, S. Förster, A. Gardiner, V. van Gastel, K. Grave, H. Groenenberg, D. de Jager, E. Klaassen, W. Pouwels, M. Smith, E. de Visser, T. Winkel, and K. Wouters. 2014. Subsidies and costs of EU energy: Final Report. Ecofys, by order of: European Commission.

Anderson, S., C. Fischer and A. Egorenkov. 2016. Overlapping Strategies for Reducing Carbon Emissions from the Personal Transportation Sector. Washington, DC: Resources for the Future.

Barker, T., S. Junankar, H. Pollitt and P. Summerton. 2007. Carbon leakage from unilateral environmental tax reforms in Europe, 1995-2005, Energy Policy 35 (2007) 6281-6292.

Böhringer, C., and K.E. Rosendahl. 2010. Green serves the dirtiest: On the interaction between black and green quotas. Journal of Regulatory Economics 37: 316-25.

Brander, J., and B. Spencer. 1985. Export subsidies and international market share rivalry. Journal of International Economics 18: 83-100.

Bruton, T.M. 2002 General trends about photovoltaics based on crystalline silicon. Solar Energy Materials and Solar Cells 72: 3-10.

Charnovitz, S. and C. Fischer. 2015. Canada—renewable energy: implications for WTO law on green and not-so-green subsidies. World Trade Review 14(02):177-210

De Gorter, H., and D.R. Just. 2010. The social cost and benefits of biofuels: The intersection of environmental, energy and agricultural policy. Applied Economic Perspectives and Policy 32: 4-32.

De Meza, D. 1986. Export Subsidies and High Productivity: Cause or Effect?. The Canadian Journal of Economics / Revue Canadienne D'economique 19 (2).

Dixit, A.K. 1984. International trade policy for oligopolistic industries. Economic Journal Conference Papers XCIV: 1-16.

Dixit, A.K., and A.S. Kyle. 1985. The use of protection and subsidies for entry promotion and deterrence. American Economic Review 75(1): 139-52.

Eaton, J., and G.M. Grossman. 1986. Optimal trade and industrial policy under oligopoly. Quarterly Journal of Economics 101: 383-406. 
U.S. Energy Information Administration (EIA). 2013. International Energy Outlook 2013. DOE/EIA-0484(2013), Washington DC.

Fischer, C. 2016. Environmental protection for sale: strategic green industrial policy and climate finance. RFF DP 16-13, Resources for the Future, Washington, DC, and FEEM Nota di Lavoro 31.2016, Fondazione Eni Enrico Mattei, Venice.

Fischer, C., and S. Charnovitz. 2015. Canada-Renewable Energy: Implications for WTO Law on Green and Not-So-Green Subsidies, World Trade Review. 14(02): 177-210.

Fischer, C., and R.G. Newell. 2008. Environmental and technology policies for climate mitigation. Journal of Environmental Economics and Management 55: 142-62.

Fischer, C. and L. Preonas. 2010. Combining Policies for Renewable Energy: Is the Whole Less than the Sum of Its Parts? International Review of Energy and Resource Economics 4 (1): $51-92$.

Fischer, C., M. Greaker, and K.E. Rosendahl. 2014. Robust policies against emission leakage: The case for upstream subsidies. CESifo Working Paper Series No. 4742.

Fischer, C., M. Greaker, and K.E. Rosendahl. 2016. Strategic technology policy as supplement to renewable energy standards. Working Paper 1/2016. School of Economics and Business, Norwegian University of Life Sciences.

Fischer, C., R. Newell and L. Preonas. 2013. Environmental and Technology Policy Options in the Electricity Sector: Interactions and Outcomes. RFF DP 13-20. Also FEEM Note di Lavoro 2014.067 and CESifo Working Paper No. 4757 (April 2014).

Gerlagh, R., \& Kuik, O. 2014. Spill or leak? Carbon leakage with international technology spillovers: A CGE analysis. Energy Economics, 45, 381-388.

Glachant, M., J. Ing, and J.P. Nicolai. 2016. The incentives to North-South transfer of climatemitigation technologies with trade in polluting goods. Mines ParisTech.

Golombek, R., and M. Hoel. 2004. Unilateral emissions reductions and cross-country technology spillovers. Advances in Economic Analysis \& Policy 4(2), Article 3.

Greaker, M., and K.E. Rosendahl. 2008. Environmental policy with upstream pollution abatement technology firms. Journal of Environmental Economics and Management 56: 246-59.

Grossman, G.M. and E. Helpman. 1994. Protection for sale. American Economic Review 84(4):833-850 
Grossman, G.M. and E. Helpman. 1995. Trade wars and trade talks. Journal of Political Economy 103 (4): 675-708.

Horstmann, I.J. and J.R. Markusen. 1986. Up the average cost curve: Inefficient entry and the new protectionism. Journal of International Economics, 20 (3-4): 225-247, May.

Hübler, M., C., Fischer, and O. Schenker. 2015. A bird in the hand is worth two in the bush: second-best analysis of European energy policy instruments. FEEM Working Paper No. 106.2015

IEA/IRENA. 2015. Joint policies and measures database. http://www.iea.org/policiesandmeasures/renewableenergy/ Accessed 09/09/2015.

Krugman, P.R. 1984. Import protection as export promotion: international competition in the presence of oligopoly and economies of scale. In H. Kierzkowski (ed.), Monopolistic competition in international trade. Oxford: Oxford University Press, 180-93.

Leahy, D., and J.P. Neary. 1999. R\&D spillovers and the case for industrial policy in an open economy. Oxford Economic Papers 51: 40-59.

Metcalf, G. and J. Stock. 2015. Integrated Assessment Models and the Social Cost of Carbon: A Review and Assessment. Available at: http://works.bepress.com/gilbert_metcalf/114/

Neary, J.P. 1994. Cost Asymmetries in International Subsidy Games: Should Governments Help Winners or Losers? Journal of International Economics 37: 197-218.

Nemet, G.F. 2006. Beyond the learning curve: Factors influencing cost reductions in photovoltaics. Energy Policy 34: 3218-32.

Nemet, G.F. 2009. Demand-pull, technology-push, and government-led incentives for nonincremental technical change. Research Policy 38: 700-709.

Organisation for Economic Co-operation and Development (OECD). 2011. Interactions between emissions trading systems and other overlapping policy instruments. General distribution document. Paris: Environment Directorate, OECD. www.oecd.org/env/taxes.

Pillai, U. and J. McLaughlin. 2013. A Model of Competition in the Solar Panel Industry. http://dx.doi.org/10.2139/ssrn.2259164

Requate, T. 2005. Timing and commitment of environmental policy, adoption of new technology, and repercussions on R\&D. Environmental and Resource Economics 31: 175-99. 
Rubini, L. 2012. Ain’t Wastin’ Time No More: Subsidies for Renewable Energy, The SCM Agreement, Policy Space, and Law Reform. Journal of International Economic Law 15 (2): 525-579.

Schaeffer, G., A. Seebregts, L. Beurskens, H.d. Moor, E. Alsema, W. Sark, M. Durstewicz, M. Perrin, P. Boulanger, H. Laukamp, and C. Zuccaro. 2004. Learning from the sun; analysis of the use of experience curves for energy policy purposes: The case of photovoltaic power. Final report, PHOTEX Project. Report ECN DEGO: ECN-C-04-035, ECN Renewable Energy in the Built Environment.

Spencer, B.J. and J.A. Brander. 1983. International R\&D rivalry and industrial strategy. Review of Economic Studies 50 (163): 707-722.

Swanson, R.M. 2006. A vision for crystalline solar cells. Progress in Photovoltaics: Research and Applications 14: 443-53.

Venables, A. J. 1985. Trade and Trade Policy with Imperfect Competition: The Case of Identical Products and Free Entry. Journal of International Economics, XIX: 1 -20.

World Bank. 2015. Carbon Pricing Watch 2015: An Advance Brief from the State and Trends of Carbon Pricing 2015 Report, to Be Released Late 2015. State and Trends of Carbon Pricing. Washington, DC: World Bank Group.

World Trade Organization (WTO). 2011. Harnessing trade for sustainable development and a green economy. Geneva. 


\section{Appendix}

\section{Analytical Results}

The results are derived and verified using Mathematica. Where possible, rather than assuming away producer heterogeneity, we focus on global average subsidies to compare the Nash equilibrium with that of the social planner. In some cases, to avoid unnecessary complications for our core intuition, we may make the following simplifications of downstream demand symmetry among the producing regions: $m_{1}=m_{2}=\left(1-m_{3}\right) / 2$.

\section{Cournot Competition}

Proof of Proposition 1(a)

With a Cournot duopoly, the optimal policy is

$$
\gamma_{C}^{*}=\frac{(a-c)}{N}, \quad \eta_{C}^{*}=0
$$

where $N=n_{1}+n_{2}$.

The Nash equilibrium, on the other hand, produces

$$
\begin{aligned}
& \gamma_{C, i}^{\mathrm{Nash}}=\frac{(a-c)\left(N+1+2 m_{3}+m_{3}\left(N-2 n_{i}-m_{3}\right)\right)}{2 n_{i}\left(N+1+2 m_{3}\right)}>0 \\
& \eta_{C, i}^{\mathrm{Nash}}=\frac{(a-c) m_{3}}{\left(N+1+2 m_{3}\right)} \geq 0 .
\end{aligned}
$$

(The expression for $\gamma_{C, i}^{\text {Nash }}$ assumes $m_{1}=m_{2}$; the downstream Nash subsidies are independent of producing region heterogeneity).

\section{Proof of Proposition 1(b)}

Sales-weighted producer subsidies are independent of the distribution of demand shares and firms among the producing regions.

The average sales-weighted upstream subsidy is less than half the optimal subsidy:

$$
\bar{\gamma}_{C}^{\mathrm{Nash}}=\frac{n_{1}}{N} \gamma_{C, 1}^{\mathrm{Nash}}+\frac{n_{2}}{N} \gamma_{C, 2}^{\mathrm{Nash}}=\frac{(a-c)}{N} \frac{\left(N+1+2 m_{3}-m_{3}\left(N+m_{3}\right)\right)}{2\left(N+1+2 m_{3}\right)}<\frac{(a-c)}{2 N}=\frac{\gamma_{C}^{*}}{2}
$$

Since the downstream subsidies are identical, even with asymmetric producing regions, their average is the same: $\bar{\eta}_{C}^{\text {Nash }}=\frac{(a-c) m_{3}}{N+1+2 m_{3}}$. 
We thus see that the sum of the subsidies is less than that of the planner, to the extent that $m_{3}>0$ :

$$
\bar{\gamma}_{C}^{\text {Nash }}+\bar{\eta}_{C}^{\text {Nash }}=\frac{(a-c)\left(N+1+\left(2-m_{3}\right) m_{3}\right)}{N\left(N+1+2 m_{3}\right)}<\frac{(a-c)}{N}=\gamma_{C}^{*} .
$$

Furthermore, the upstream share is decreasing in $N$ and $m_{3}$ :

$$
\frac{\bar{\gamma}_{C}^{\text {Nash }}}{\bar{\gamma}_{C}^{\text {Nash }}+\bar{\eta}_{C}^{\text {Nash }}}=1-\frac{N m_{3}}{N+1+m_{3}\left(2-m_{3}\right)} \geq \frac{1}{1+1 / N}
$$

\section{Proof of Proposition 1(c)}

When $m_{3}=0, \eta_{C, i}^{\text {Nash }}=\eta^{*}=0$, so no downstream subsidies are used. Upstream, the

average subsidy equals that of the planner: $\bar{\gamma}_{C}^{\text {Nash }}=\gamma^{*}$. However, the individual upstream subsidies depend on the extent to which each region is a net importer or exporter:

$\gamma_{C, 1}^{\text {Nash }}=\frac{(a-c)\left(1+m_{1}-m_{2}\right)}{2 n_{1}}$. The producing region with greater consumption and fewer firms (implying status as a net importer) has a higher subsidy.

Proof of Proposition 1(d)

When maximizing $\left\{W_{1}+W_{2}\right\}$, the jointly optimal subsidies are

$$
\begin{aligned}
& \gamma_{C}^{\text {Joint }}=\frac{(a-c)\left(2-N-m_{3}\right)}{2 N}<0 ; \\
& \eta_{C}^{\text {Joint }}=\frac{(a-c)}{2}>\eta_{C, i}^{\text {Nash }} \geq 0 .
\end{aligned}
$$

Proof of Proposition 2(a)

Suppose that downstream subsidies are prohibited. The global optimum is unchanged, but the Nash equilibrium provides a smaller subsidy. We also solve for the optimal subsidies for the jointly maximized welfare of the producer states, and find that it is yet smaller:

$$
\begin{aligned}
& \left.\gamma_{C}^{*}\right|_{\eta=0}=\frac{(a-c)}{N} \\
& \left.\bar{\gamma}_{C}^{\text {Nash }}\right|_{\eta=0}=\frac{(a-c)\left(\left(1-N m_{3}\right)+N+1\right)}{N\left(\left(1+m_{3}\right)+N+1\right)}<\gamma_{C}^{*} \\
& \left.\gamma_{C}^{\text {Joint }}\right|_{\eta=0}=\frac{(a-c)\left(1-N m_{3}\right)}{N\left(1+m_{3}\right)}<\left.\gamma_{C}^{\text {Nash }}\right|_{\eta=0}<\gamma_{C}^{*}
\end{aligned}
$$


This reveals the tension between the producer states' incentives to restrict competition, their noncooperative incentives to protect market share, and global incentives to address the market failure of imperfect competition.

\section{Proof of Proposition 2(b)}

If upstream subsidies are prohibited, and one cannot subsidize downstream in the third country, then the downstream subsidy must balance its effectiveness to internalize the upstream market failure with its effects on the terms of trade. The planner will want a smaller downstream subsidy than the (unconstrained) optimal upstream subsidy, to the extent that $m_{3}>0$ :

$$
\left.\eta_{C}^{*}\right|_{\gamma=0}=\frac{(a-c)}{N+m_{3}(2+1 / N)}<\gamma_{C}^{*}
$$

The Nash equilibrium is more complicated, because producer heterogeneity — on both the supply and the demand side - influences the constrained strategic subsidy. Assuming fully symmetric producers (i.e., $m_{1}=m_{2}, n_{1}=n_{2}$ ), we see that the Nash subsidy is still less than the optimal constrained downstream subsidy:

$$
\left.\eta_{C}^{\mathrm{Nash}}\right|_{\gamma=0}=\frac{(a-c)\left(1+m_{3}\right) N}{2(1+N)\left(N+m_{3}\right)+1-m_{3}^{2}}
$$

Note that when upstream subsidies are prohibited, if the entire downstream market is in the third country (i.e., $m_{3}=1$ ), then the Nash equilibrium replicates the optimal policy if the producers have equal upstream market shares $\left(n_{1}=N / 2\right)$ :

$$
m_{3} \rightarrow 1:\left.\quad \eta_{i, C}^{*}\right|_{\gamma=0} \rightarrow \frac{(a-c) N}{(1+N)^{2}} ;\left.\quad \eta_{i, C}^{\mathrm{Nash}}\right|_{\gamma=0} \rightarrow \frac{(a-c) 2 n_{i}}{(1+N)^{2}}
$$

On the other hand, if there is no third country market, the symmetric Nash equilibrium underprovides the downstream subsidy (we demonstrate this result with $m_{1}=m_{2}, n_{1}=n_{2}$ ):

$$
m_{3} \rightarrow 0:\left.\quad \eta_{C}^{\mathrm{Nash}}\right|_{\gamma=0}=\frac{(a-c)}{N+(N+1+1 / N)}<\frac{(a-c)}{N}=\left.\eta_{C}^{*}\right|_{\gamma=0}
$$

\section{Unilateral Policies}

If subsidies can be implemented only in one jurisdiction, then $\left.\gamma_{1}^{*}\right|_{\gamma_{2}=0, \eta_{2}=0}=(a-c) / n$. A strategic region 1, however, would subsidize downstream, as well as upstream, with the sum still less than the constrained optimal subsidy: 


$$
\begin{aligned}
& \left.\gamma_{1}\right|_{\gamma_{2}=0, \eta_{2}=0}=\frac{(a-c)\left(3+4 n\left(1-m_{3}\right)+m_{3}\left(2-m_{3}\right)\right)}{4 n\left(1+2 n+m_{3}\right)}>0 \\
& \left.\eta_{1}\right|_{\gamma_{2}=0, \eta_{2}=0}=\frac{(a-c)\left(1+m_{3}\right)}{2 n\left(1+2 n+m_{3}\right)}>0 \\
& \left.\gamma_{1}\right|_{\gamma_{2}=0, \eta_{2}=0}+\left.\eta_{1}\right|_{\gamma_{2}=0, \eta_{2}=0}=\frac{(a-c)\left(3-m_{3}\right)}{4 n}<\left.\gamma_{1}^{*}\right|_{\gamma_{2}=0, \eta_{2}=0}
\end{aligned}
$$

\section{Downstream Externality}

With a nonzero external benefit from downstream consumption of the green good, the analytical expressions for the Nash equilibrium subsidies become too elaborate to repeat here, since the second market failure also interacts with the first market failure of imperfect competition. Here, to develop intuition, we either focus on the downstream externality by itself (taking the limit of the optimal subsidies as $N \rightarrow \infty$ ) or assume symmetry among the producer regions.

Proof of Proposition 3

This follows from Proposition 1(a), taking the limit of the optimal subsidies as $N \rightarrow \infty$.

\section{Proof of Proposition 4}

With imperfect competition, the optimal policy is

$$
\begin{aligned}
& \gamma_{i}^{*}=\mu_{3} v_{G}+\frac{a-c}{N}+\frac{v_{G} \bar{\mu}}{N} \\
& \eta_{i}^{*}=\left(\mu_{i}-\mu_{3}\right) v_{G}
\end{aligned}
$$

Thus, as $N \rightarrow \infty, \gamma_{i}^{*} \rightarrow \mu_{3} v_{G}$.

Proof of Proposition 5(a)

The symmetric Nash equilibrium (denoted with $X$ and assuming $m_{1}=m_{2}, n_{1}=n_{2}$, and $\left.\mu_{2}=\mu_{1}\right)$ produces

$$
\begin{aligned}
& \gamma_{X}^{\text {Nash }}=\gamma_{C}^{\text {Nash }}+\frac{\mathrm{Z}}{N\left(1+N+2 m_{3}\right)} v>0 \\
& \eta_{X}^{\text {Nash }}=\mu_{X} v+\eta_{C}^{\text {Nash }}-\frac{\bar{\mu}+m_{3} \mu_{3}}{\left(1+N+2 m_{3}\right)} v \geq 0 .
\end{aligned}
$$

Where $\mathrm{Z}=\left(1-m_{3}\right)\left(\left(1+3 m_{3}+2 N\right) \mu+2 m_{3}\left(N+m_{3}\right) \mu_{3}\right)$ 
But without imposing any assumptions of symmetry, we find that $\gamma_{i}^{\text {Nash }} \rightarrow 0$, and $\eta_{i}^{\text {Nash }} \rightarrow v_{i} \mu_{i}$ as $N \rightarrow \infty$.

Proof of Proposition 5(b)

With $m_{3}=0$, and $v_{1}=v_{2}=v_{G}$, we can demonstrate in Mathematica (without imposing symmetry) that $\bar{\gamma}^{\text {Nash }}+\eta_{i}^{\text {Nash }}=v_{G} \mu_{i}$; thus, each region has optimal deployment incentives.

\section{Proof of Proposition 5(c)}

Simplifying the difference between the Nash and globally optimal upstream subsidies, we see that

$$
\bar{\gamma}^{\mathrm{Nash}}+\eta_{i}^{\mathrm{Nash}}-\left(\bar{\gamma}^{\mathrm{G}}+\eta_{i}^{\mathrm{G}}\right)=\underbrace{\frac{m_{3}(a-c)}{N\left(1+N+2 m_{3}\right)}}_{\bar{\gamma}_{C}^{\mathrm{Nash}}+\eta_{i, C}^{\mathrm{Nath}}-\left(\bar{\gamma}_{C}^{\mathrm{G}}+\eta_{i, C}^{\mathrm{G}}\right)}-\frac{m_{3} v_{G}\left(\mu_{3}(1+N)-m_{1} \mu_{1}-m_{2} \mu_{2}\right)}{N\left(1+N+2 m_{3}\right)} .
$$

Thus, as long as $\mu_{3} \geq\left(m_{1} \mu_{1}+m_{2} \mu_{2}\right) /(1+N)$, the interaction between the downstream externality and the presence of the third market exacerbates the underprovision of subsidies for the green good.

\section{Scale Effects}

Proof of Proposition 6

Solving for the globally optimal subsidies, and substituting the value of $c_{0}$, we find

$$
\begin{aligned}
& \gamma_{S, i}^{*}=\frac{\left(a-c_{0}\right)(b+g(N-1))}{N(b-2 g)}=\frac{(a-c)}{N}\left(\frac{(b-g)^{2}+N g(b-g)}{(b-g)^{2}-g^{2}}\right)>\frac{(a-c)}{N} \\
& \eta_{S, i}^{*}=0
\end{aligned}
$$

Thus, the optimal subsidy is higher than that to correct for imperfect competition alone, and no downstream subsidies are needed.

The optimal upstream subsidy implies optimal global output of $Y_{S}^{*}=\frac{(a-c)(b-g)}{b(b-2 g)}$, using our value of $c_{0}$. We thus restrict our scale parameter to $g<b / 2$.

\section{Proof of Proposition 7}

Solving for the symmetric Nash equilibrium subsidies, we get 


$$
\begin{aligned}
& \gamma_{S, i}^{\text {Nash }}=\frac{2\left(a-c_{0}\right)(b-g)\left((b-g)\left(1+2 m_{3}-m_{3}^{2}\right)+b N\left(1-m_{3}\right)\right)}{N \zeta}>0 \\
& \eta_{S, i}^{\text {Nash }}=\frac{\left(a-c_{0}\right) b\left((b-g) 2 m_{3}+g N\left(1-m_{3}\right)\right)}{\zeta}>0
\end{aligned}
$$

where $\zeta=2 b^{2}\left(N+1+2 m_{3}\right)-b g\left(4 N+5\left(1+2 m_{3}\right)-3 m_{3}^{2}\right)+g^{2}\left(1+2 m_{3}-m_{3}^{2}\right)$. Note that $\zeta>0$ if $g<b / 2$.

Next, substituting the value of $c_{0}$, we have

$$
\begin{aligned}
& \gamma_{S, i}^{\text {Nash }}=\frac{2(a-c)(b-g)^{2}\left((b-g)\left(1+2 m_{3}-m_{3}^{2}\right)+b N\left(1-m_{3}\right)\right)}{N \zeta} \\
& \eta_{S, i}^{\text {Nash }}=\frac{(a-c)(b-g)\left(2 m_{3}(b-g)+g N\left(1-m_{3}\right)\right)}{\zeta}
\end{aligned}
$$

Scale effects depress total Nash subsidy contributions, relative to imperfect competition alone:

$$
\begin{aligned}
& \left(\gamma_{S, i}^{\text {Nash }}+\eta_{S, i}^{\mathrm{Nash}}\right)-\left.\left(\gamma_{C, i}^{\mathrm{Nash}}+\eta_{C, i}^{\mathrm{Nash}}\right)\right|_{m_{3}=0}=-\frac{(a-c)}{N} \frac{g\left(\left(N^{2}-1\right) b(b-g)+g(2(b-g)+N)\right.}{b\left(2(N+1) b^{2}-(4 N+5) b g+(N+3) g^{2}\right)}<0 \\
& \left(\gamma_{S, i}^{\mathrm{Nash}}+\eta_{S, i}^{\mathrm{Nash}}\right)-\left.\left(\gamma_{C, i}^{\mathrm{Nash}}+\eta_{C, i}^{\mathrm{Nash}}\right)\right|_{m_{3}=1}=-\frac{(a-c)}{N} \frac{2 g}{b(N+3)}<0
\end{aligned}
$$

However, depending on $g$, the use of upstream subsidies in this mix may be higher or lower.

\section{Proof of Proposition 8}

Setting $m_{3}=0$, we have

$$
\gamma_{S, i}^{\mathrm{Nash}}+\left.\eta_{S, i}^{\mathrm{Nash}}\right|_{m_{3}=0}=\frac{(a-c)(b-g)\left(2(b-g)((N+1) b-g)+b g N^{2}\right)}{b N\left(2(N+1) b^{2}-(4 N+5) b g+(N+3) g^{2}\right)}
$$

The optimal subsidy package in this case is

$$
\gamma_{S, i}^{*}+\left.\eta_{S, i}^{*}\right|_{m_{3}=0}=\left.\gamma_{S, i}^{*}\right|_{m_{3}=0}=\frac{(a-c)(b-g)(b+(N+1) g))}{N b(b-2 g)}
$$

We can then show that

$$
\gamma_{S, i}^{*}-\gamma_{S, i}^{\mathrm{Nash}}-\left.\eta_{S, i}^{\mathrm{Nash}}\right|_{m_{3}=0}=\frac{(a-c)(b-g)^{3} g(N+1)^{2}}{(b-2 g) b N\left(2(N+1) b^{2}-(4 N+5) b g+(N+3) g^{2}\right)}>0
$$

Thus, for $\mathrm{g}>0$, the Nash duopoly no longer replicates the social optimum. 